\title{
Vocal aging and adductor spasmodic dysphonia: Response to botulinum toxin injection
}

\author{
Michael P Cannito \\ Joel C Kahane \\ Lesya Chorna
}

School of Audiology and SpeechLanguage Pathology, The University of Memphis, Memphis, TN, USA
Correspondence: Michael P Cannito School of Audiology and Speech-Language Pathology, The University of Memphis, 807 Jefferson Avenue, Memphis, TN 38I05, USA

Tel + I 90I 6785800

$\mathrm{Fax}+\mid$ 90। 525 I282

Email mcannito@memphis.edu

\begin{abstract}
Aging of the larynx is characterized by involutional changes which alter its biomechanical and neural properties and create a biological environment that is different from younger counterparts. Illustrative anatomical examples are presented. This natural, non-disease process appears to set conditions which may influence the effectiveness of botulinum toxin injection and our expectations for its success. Adductor spasmodic dysphonia, a type of laryngeal dystonia, is typically treated using botulinum toxin injections of the vocal folds in order to suppress adductory muscle spasms which are disruptive to production of speech and voice. A few studies have suggested diminished response to treatment in older patients with adductor spasmodic dysphonia. This retrospective study provides a reanalysis of existing pre-to-post treatment data as function of age. Perceptual judgments of speech produced by 42 patients with ADSD were made by two panels of professional listeners with expertise in voice or fluency of speech. Results demonstrate a markedly reduced positive response to botulinum toxin treatment in the older patients. Perceptual findings are further elucidated by means of acoustic spectrography. Literature on vocal aging is reviewed to provide a specific set of biological mechanisms that best account for the observed interaction of botulinum toxin treatment with advancing age.
\end{abstract}

Keywords: vocal aging, adductor spasmodic dysphonia, botulinum toxin, voice quality, speech fluency

\section{Introduction}

Phonatory function is known to decline as a result of normal aging due to changes in the viscoelastic properties of the vocal folds along with other laryngeal biomechanical and neurologic changes (Kahane 1996). Moreover, movement disorders that tend to be more prevalent in older individuals (eg, Parkinson's disease) also tend to negatively impact phonatory ability. The relationship between normal aging and co-occurring voice disorders, and particularly the impact of vocal aging on treatment of voice disorders, has not been well studied. One such movement disorder is adductor spasmodic dysphonia (ADSD), a type of focal laryngeal dystonia that impedes voice production and usually has debilitating effects on speech communication. ADSD affects laryngeal function in adults throughout the lifespan. This review examines the voice disorder of ADSD and the effect of vocal aging on its response to a specific treatment, botulinum toxin (BT) injection of the vocal folds. In addition, a retrospective reanalysis of recently published data consisting of expert listeners' perceptual ratings of ADSD speakers before and after BT injection is provided to further examine the influence of aging on treatment outcome.

\section{Adductor spasmodic dysphonia}

Adductor spasmodic dysphonia (ADSD) is an uncommon voice disorder characterized by intermittent voice stoppages, or breaks in voicing associated with over adduction of the vocal folds, resulting in a "strained-strangled" voice quality, and disfluent, 
effortful speech production. These behaviors result from intermittent adductor spasms or squeezing of the vocal folds in the closed direction. ADSD is diagnostically differentiated from abductor spasmodic dysphonia (ABSD) in which the vocal folds spasm in the open direction, resulting in intermittent breathy dysphonia. ADSD also is diagnostically differentiated from dyasarthria, in which the muscles of articulation also exhibit movement abnormalities affecting speech, but with which it may co-occur. ADSD is typically regarded as a type of focal, action induced, laryngeal dystonia (Blitzer et al 1998). Central nervous system dysfunction in a number of supranuclear brain regions associated with laryngeal motor control have been implicated in the disorder, with support from a variety of neuroimaging techniques (Finitzo and Freeman 1989; Devous et al 1990; Haslinger et al 2005; Ali et al 2006); however, no specific locus of neurologic dysfunction or precipitating disease state has as yet emerged as an immediate causative explanation for the majority of persons with ADSD. ADSD is considered to be a relatively uncommon voice disorder; however, its precise incidence and prevalence remain unknown. It tends to affect women more frequently than men; however, sex ratios vary markedly from study to study. Onset typically occurs during middle age; but earlier and later onset ages have been reported in the literature (Aronson 1990). Following onset, there is typically a worsening of dysphonia over the first six months to a year. Beyond that time, the voice disorder typically stabilizes and does not usually continue to deteriorate. Although the phonatory symptoms may co-occur with movement disorders elsewhere in the body (eg, dystonia or tremor of the neck or limbs), ADSD also frequently occurs as an isolated phenomenon, and may or may not be associated with laryngeal tremor.

Some common features of untreated ADSD (middle panels) and nondysphonic control voices (top panels) are illustrated in Figures 1 and 2, which provide acoustic spectrographic images or "voice prints." Each panel is a visual representation of sound produced during vocalization of the phrases "... raindrops in the air ..." (Figure 1) and "When the sunlight ..." (Figure 2). Sound frequency is represented on the vertical axis (from 0 to $5 \mathrm{KHz}$ ), while elapsed time is represented on the horizontal axis. The phrase duration (msec) is provided in the lower right corner of each panel. Darkness of shading indicates sound intensity. A younger, 38 year old female speaker with ADSD and her matched normal control are presented in Figure 1. Figure 2 presents an older, 74 year old female ADSD speaker with matched normal control.
Inspection of the top panels of Figures 1 and 2 reveal that the normal phrases were produced rapidly with smooth transitions between sounds, syllables and words. Voiced sounds such as vowels appear as vertical striations spread across the frequency range. Each striation represents one cycle of vocal fold vibration, occurring closely together in time at a rate of approximately 220 cycles per second. Voiceless sound, such as the /s/ in "sun" appears as a fuzzy or stippled feature in the higher frequency range in the absence of vertical striations. The only breaks in the normal flow of sound were brief silences (lack of shading less than $20 \mathrm{msec}$ ) before and after the voiceless /s/ sound in "sun."

Prior to BT injection, the ADSD speakers (middle panels) exhibit dramatic prolongation of their phrases, taking more than twice as much time as their normal counterparts. ADSD productions also exhibit several voice breaks of long duration, during which the vocal folds are compressed tightly together (adductor spasms). It is notable that some voice breaks occur within vowels (eg, "su-un"), contributing to an overall impression of disfluency. Glottal stops occur as isolated vertical striations at moments when the adducted vocal folds were blown apart in an effort to reinitiate voicing. Strained-strangled voicing is characterized by widely and irregularly spaced vertical striations indicating slow and aperiodic vocal fold vibration.

\section{BT injection of the vocal folds}

Behavioral voice therapy has not proven effective for treating ADSD (Cannito and Woodson 2000). Despite a variety of surgical options (eg, sectioning of a recurrent laryngeal nerve), injection of the true vocal fold(s) with BT is now generally regarded as the preferred method of treatment (Cannito and Woodson 2000). BT injection weakens neuromuscular contraction of the vocal folds by interfering with release of acetylcholine (ACh) at the neuromuscular junction (NMJ). This induced partial paralysis reduces the effect of adductor spasms on voice production and, following a brief period of intense breathiness, benefit may last up to three months, after which the effects of the toxin gradually subside and re-injection is necessary (Ludlow 1995). BT is typically delivered to the thyroaretenoid muscle (TA) of a vocal fold using transcutaneous injection through the neck, with needle placement verified via electromyography (Miller et al 1987; Blitzer and Brin 1992). Alternatively, transoral or transnasal approach may be employed using nasoendoscopy for visual guidance (Ford et al 1992; Rhew et al 1994). Injections may also be either unilateral or bilateral, with little evidence supporting one method over the other, and 


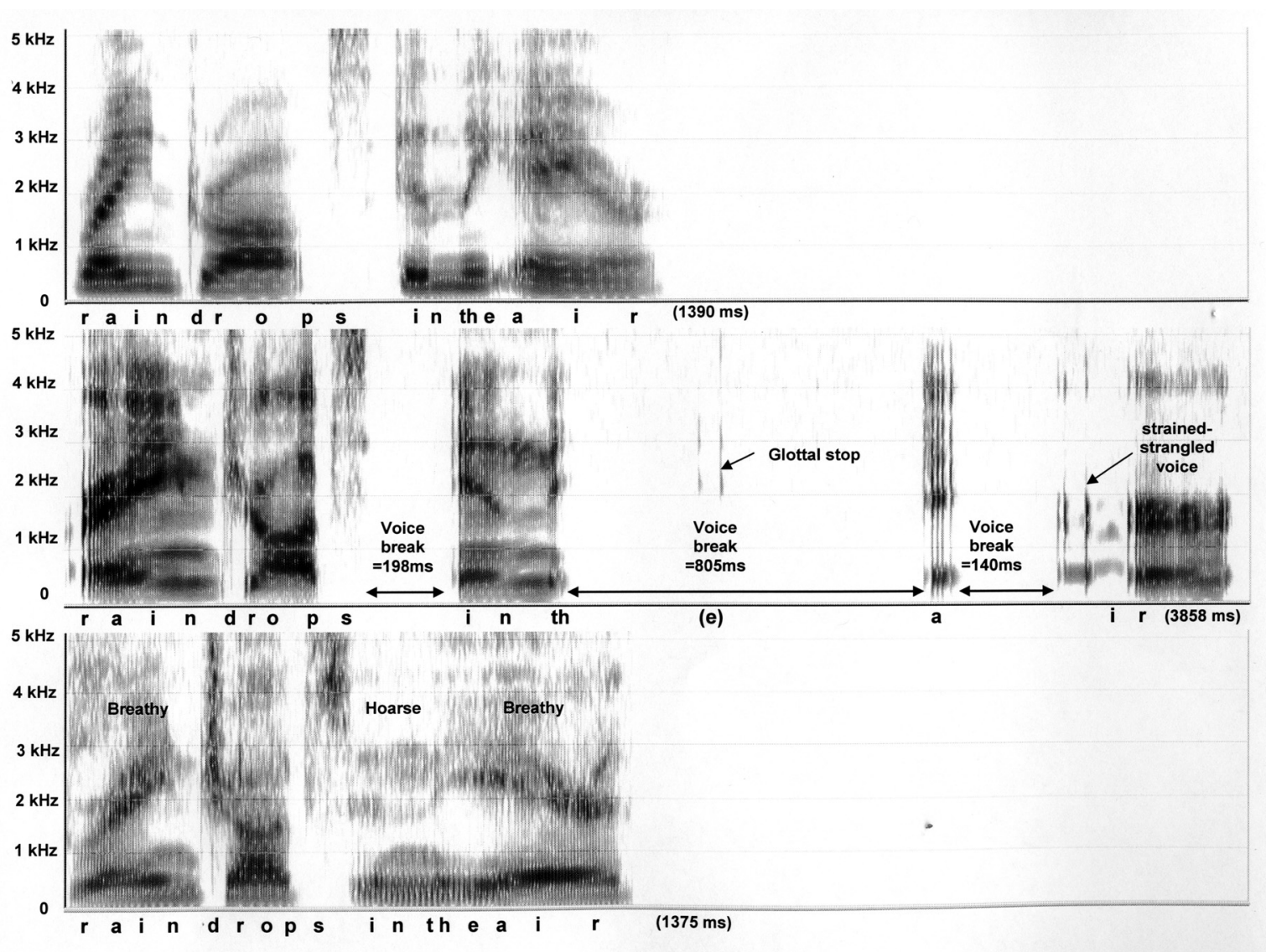

Figure I Spectrograms of the phrase “... raindrops in the air ..." spoken by a 38 year old female: normal control subject is depicted on the top panel, ADSD before BT injection is on the middle, and ADSD after BT injection is on the bottom panel.

dosages employed vary widely within and across studies (Boutsen et al 2002). The variation in dosage level reported by different clinicians is based, in part on the severity of presenting signs and symptoms, and/or whether the injection is unilateral or bilateral. It has been suggested that smaller dosages injected bilaterally may have a similar effect on voice production in ADSD as substantially larger unilateral dosages (Woodson 1994).

Efficacy of BT injection for ADSD is well established (Truong et al 1991; Blitzer and Brin 1992; Boutsen et al 2002). Following treatment there are fewer voice breaks and fewer episodes of strained strangled dysphonia, and pitch becomes more stable. Recent studies, however, also have demonstrated that even during post-injection periods when benefit is considered optimal, both acoustic and perceptual indices continued to significantly differentiate ADSD from control speakers (Langveldt et al 2001; Sapienza et al 2002; Cannito et al 2004). This was especially true of phonatory aperiodicity or "roughness" and "breathiness" present in both sustained vowels and connected speech. However, the effect of aging upon treatment outcome in ADSD has not been well studied.

Figures 1 and 2 (bottom panels) provide spectrograms of post-injection ADSD speech. It is apparent in Figure 1 that, following BT injection, the younger speaker achieved an almost normal appearing production. Syllable timing is rapid, with smooth transitions between sounds and syllables and vertical striations are narrowly and regularly spaced. The post treatment voice is mildly breathy and hoarse, however, as indicated by light stippling in the high frequency range overlaid upon the vertical striations for voiced sounds. This is due to air turbulence associated with slight weakness of the vocal folds following injection. In Figure 2, the older speaker's post-injection production (bottom panel) is even slower than pre-injection (middle panel). Following injection, voice breaks and strain-strangled voice remain in evidence; however, high frequency stippling overlaid upon the vertical striations of vowel sounds indicates that the voice is also breathy due to BT-induced weakness. 


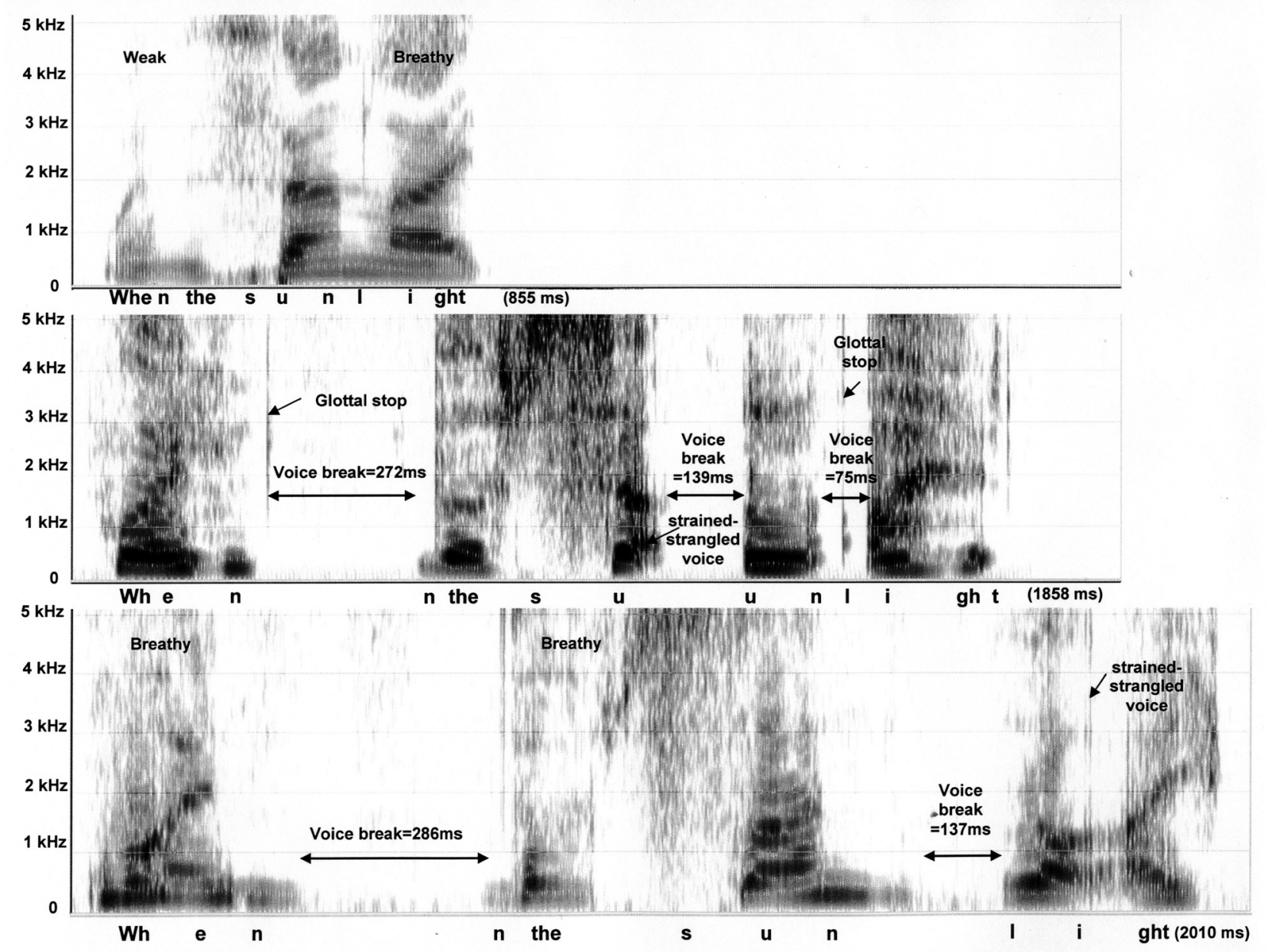

Figure 2 Spectrograms of the phrase "When the sunlight ..." spoken by a 74 year old female: normal control subject is depicted on the top panel, ADSD before BT injection is on the middle, and ADSD after BT injection is on the bottom panel.

\section{Action of BT on the motor unit}

BT type A is a medication that has been used for nearly three decades to treat hyperactive muscle disorders, a variety of dystonias and movement disorders (Schantz and Johnson 1992). The mechanism for its action is that the toxin prevents release of membrane-bound ACh at the NMJ of striated muscle and causes a denervation and a paralysis of the muscle (Simpson 1992). The mechanism by which this occurs appears to result from toxin entering the nerve endings through endocytosis and inhibiting release of the vesicle-bound $\mathrm{ACh}$ within the nerve terminal itself. The $\mathrm{BT}$ is internalized into the neuron and then acts as a zinc-dependent endoprotease to disrupt some of the peptides required for release of the ACh. This action may take a couple of weeks to be completed. It destructs the NMJ resulting in muscular paralysis. It may take up to six months post injection, for the terminal axonal endings and the neuromuscular junctions to reconstitute themselves. Hambleton (1993) has noted that the toxin also enhances the ongoing turnover of NMJs, thus initiating physical recovery before full functional recovery. The changes in muscle following BT injection have been studied (Duchen 1970, 1972). It appears that muscle atrophy induces axonal sprouting. However, the regenerating axons appeared to branch in complex arrangements which were unable to establish functional connections for several weeks after injection. Once connections were established, the process of reconstituting denervated muscle proceeded in a normal fashion. Pestronk and Drachman (1978) demonstrated that the amount of sprouting was correlated with the number of ACh receptors which in turn played an important role in inducing sprouting in denervated muscle.

De Paiva et al (1999) studied the functional repair of motor end plates following BT injection. They found that the initial axonal sprouts were responsible for nerve-muscle transmission. A distinct second phase in the restoration process was found. It consisted in turning over of function 
to the original terminals, causing the now superfluous (initial) sprouts to withdraw. The authors conclude that these initial sproutings are "functionally" essential to the repair process in paralyzed muscles. These findings support earlier work by Duxson and Vrbová (1985), who showed that the rate at which superfluous sproutings (initial nerve terminals) retract from the developing NMJ is regulated by the frequency of activation of the muscle. Thus, de Paiva et al (1999) conclude that axonal growth occurring as a secondary effect of BT injection, does not permanently establish new NMJs. Rather, the initial axonal sprouting serves as a mechanism to initially activate paralyzed muscle fibers in the early weeks-to-months post-injection. As the parent end plate/muscle fibers become more active, the initial sproutings, now superfluous, become withdrawn. Of note is the interaction between age and BT effect, relative to duration of motor end plate response. Both Knutsson et al (1969) and Davidson and Ludlow (1996) found that the duration of motor end plate response and its variability were significantly, positively correlated with age. Davidson and Ludlow (1996) attributed the increased duration of motor unit response to the inefficiency of collateral sprouting which they noted begins to decrease in one year. Thus, the refinement of motor unit activity may last for years after injection ( 3 years in subjects in their study).

\section{Normal vocal aging The role of the vocal folds in vocal aging}

In the current paper, the balance of this literature review will focus on the vocal folds, because of their central importance to mechanics of ADSD and its treatment with BT.

Structures in the larynx undergo a variety of agerelated changes. The heterogeneity of affected structures is illustrated in Figure 3. It shows a complex organization of tissues which are the underpinnings for such diverse functions as protection of epithelial surfaces through lubrication and immunologic benefits of laryngeal glands, imbuing viscoelastic and biomechanical properties to cartilages and the vocal folds and enabling them to respond to various mechanical stressors to which they are exposed, as well as providing a skeletal support for the laryngeal cavity and other soft tissues. The neuromuscular tissues are involved in important protective reflexes and regulatory mechanisms of the airways. Voice production is the byproduct of many of these intrinsic properties of the larynx, but especially the vocal folds whose unique responses to aerodynamic forces create the source of energy for speech production.

\section{Epithelium and lamina propria of the vocal folds}

Morphologic changes in the vocal folds of aged speakers involve changes in the epithelium, lamina propria, and neuro-muscular tissues. These changes neither occur uniformly, nor to the same extent in men and women. Given the layered structure of a vocal fold, changes in it must be viewed from the superficial surface inwardly. The surface epithelium becomes thinner and altered in surface architecture with aging (Noell 1962). These surfaces are less robust and made more vulnerable by the effects of atrophy of mucous glands. The glands reduce the quantity and quality of their secretion (Gracco and Kahane 1989; Sato and Hirano 1998) which changes the normal rheologic properties of the surface, reduces protection against contact pressures and aerodynamic shearing forces, and compromises mucocilliary transport and immunologic competency. Distinctive characteristics of involution to the mucosa and submucosal connective tissues (lamina propria) have also been noted. This observation is important, because the layers of the lamina propria contribute in distinctive ways to the mobility of the vibrating surface of the vocal fold and to the longitudinal stability of it during vibration (Gray et al 1999). Several changes in the lamina propria occurred with aging had been studied extensively. These involutional changes include alteration in the structure and organization of the elastic and collagenous fibers ( Kahane 1987; Sato and Hirano 1997; Hirano et al 2000; Sato et al 2002; Madruga de Melo et al 2003), reduction in the ability to synthesize these fibrous proteins (Sato et al 2004), alterations in composition and decrease in quantity of ground substance (Thibeault et al 2002). Figure 4 is an illustration of these types of changes, providing cross sections of adult vocal folds at various ages. The effects of altering the physical properties of the lamina propria include reduction of the tensile strength of the scaffolding of the vocal folds, alteration of its viscoelastic properties (ie, making it stiffer) and in the shape of the vibrating edges of the vocal folds. These changes, reduce stability of the vocal folds during vibration and adversely affect vocal efficiency, contributing to voice quality deviations (Honjo and Isshiki 1980; Linville 1996).

\section{Intrinsic laryngeal muscles}

Changes in intrinsic laryngeal muscles have been found in aging larynges (Ferreri 1959; Hommerich 1972; Sato and Tauchi 1982; Rodeno et al 1993) and have been attributed to reduction in muscle force and efficiency. These aging muscle changes may occur more generally in the animal kingdom, as evidenced by Mardini (1987), who found that in an aging baboon, the TA muscle contracted more slowly, fatigued more readily, and took longer to recover than in younger animals. In rats and 


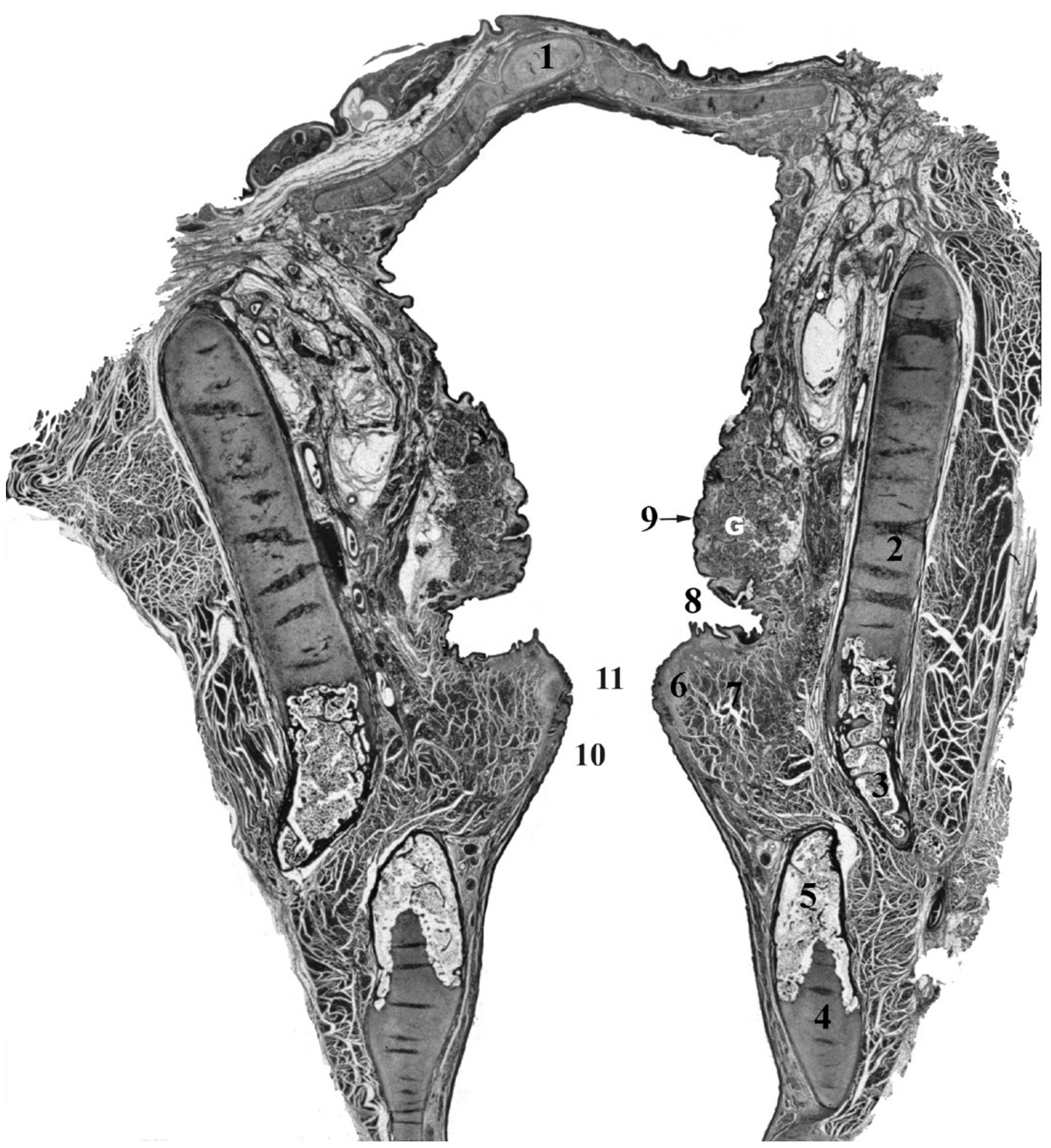

Figure 3 Coronal section of the larynx from 56 year old female illustrating major structural landmarks. Safran-Hematoxylin Stain, 2.5x original magnification. I - epiglottis, 2 - unossified thyroid cartilage, 3 - ossified portion of thyroid cartilage, 4 - unossified cricoid cartilage, 5 - ossified portion of cricoid cartilage, 6 - lamina propria of vocal fold, 7 - thyroarytenoid muscle (the major constrictor of vocal fold), 8 - laryngeal ventricle (lined of glandular epithelium), 9 - vestibular fold with $G$ - mucous-serous glands, 10 - conus elasticus, II - glottal space.

humans, who have been studied most extensively, TA muscle changes have been postulated to result from arteriosclerotic changes in the vessels (Ferreri 1959; Hommerich 1972) or from disturbance in sympathetic innervations (Bach et al 1942). Disagreement exists as to whether aging changes affect both sexes equally and all muscles uniformly (Carnevalle-Ricci 1937; Ferreri 1959). Some authors maintain that there is a predilection for the adductor muscles (Bach et al 1942) to be more affected than the abductors (Malmgren and Gacek 1981). Suzuki et al (2002) reported that in rat laryngeal muscles, aging had greatest affect on adductory function by altering fiber type composition to an isoform of myosin, which is slower contracting and similar to what occurs in denervation. The TA muscle - the principal muscle of the vocal fold - has been studied extensively in the last two decades. Its involution has been attributed to atrophy which has been causally linked to 
A
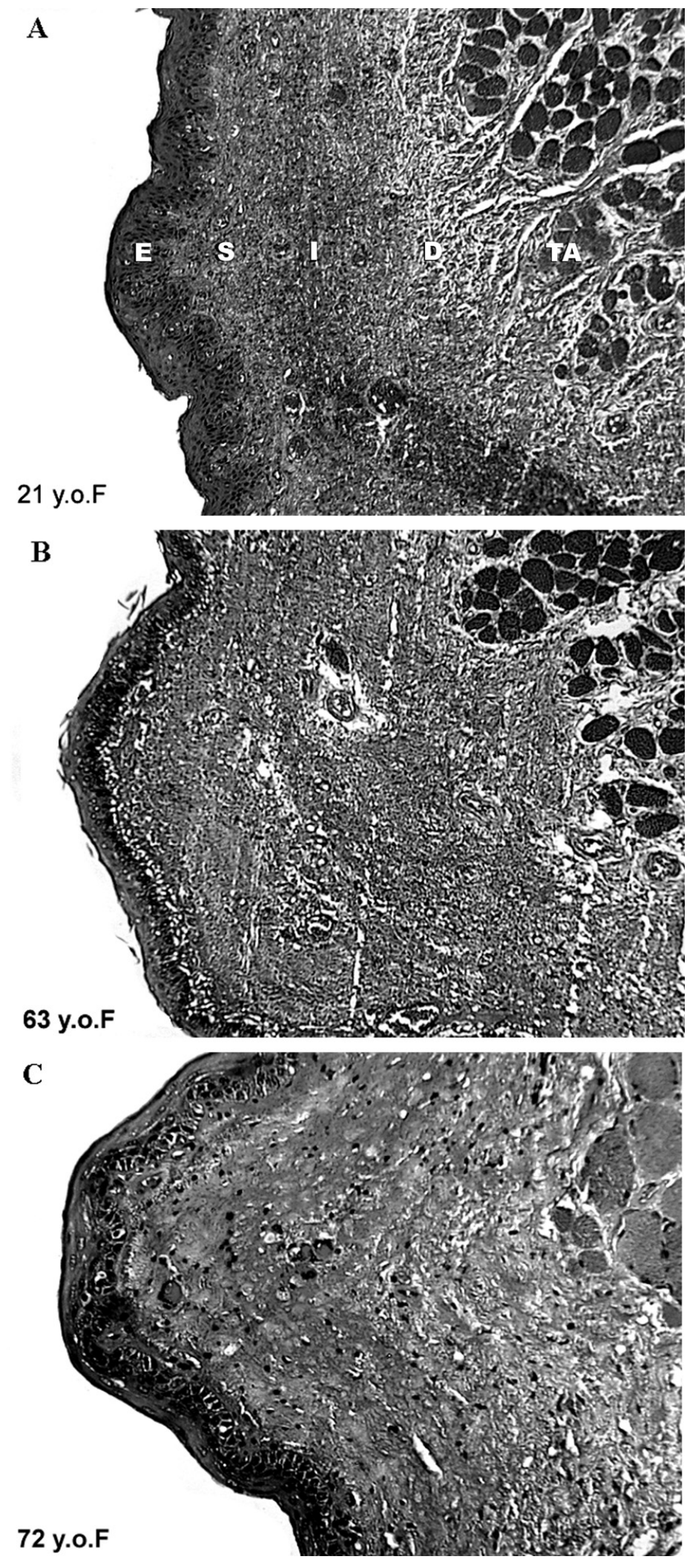

Figure 4 Coronal sections of the vocal fold from 2 lyears old (A), 63 years old (B) and 72 years old (C) females illustrating age related changes in the epithelium and lamina propria. Safran-Hematoxylin Stain, 20x original magnification. E - epithelium, S - superficial layer of the lamina propria, I - intermediate layer of the lamina propria, D - deep laryner of the lamina propria. Portions of the adjacent thyroarytenoid muscle (TA), which form a part of the body of the vocal fold, are also illustrated. 
altered metabolic processes (Kersing and Jennekens 2004), aging contractile proteins (Mardini et al 1987), alteration in fiber type composition (Rodeno et al 1993; Malmgren et al 1999; Suzuki et al 2002) and degenerative changes caused by subtle amounts of denervation and poor or inefficient reconstitution of NMJs (Prakash and Sieck 1998). Sato and Tauchi (1982) found that aging appeared to have a differential effect on fiber types within the TA muscle. Slow fatigue resistant (type I) fibers were found to degenerate rapidly than fast fatigue prone (type II) fibers after age 60. Type II fibers declined more rapidly after age 70 and both types significantly declined after age 80 . The functional consequences during voice production of these muscle changes relate to (a) inaccurate positioning of the vocal folds for various voicing gestures, (b) reduced adductory forces needed to approximate the vocal folds during voice production and (c) altered or deficient muscular-mechanics needed to transiently change the physical properties of the vocal folds for rapid adjustments for modulation of pitch during speech.

\section{Incomplete glottic closure}

Incomplete closure of the glottis (space between the vocal folds) is one of the characteristic deficits in vocal mechanics observed in the aging speaker (Tanaka et al 1994). This condition referred to as bowing of the vocal folds is thought to result from atrophy of the lamina propria and thyroarytenoid muscle. This condition is illustrated video-stroboscopically in Figure 5. The lack of complete closure of the glottal chink by the adducted vocal folds may alter voice in several ways: (a) by reducing subglottal pressure required to maintain vocal fold oscillation and allow for adequate loudness; (b) allowing for the introduction of a competing noise to the vocal fold signal. This results from unmodulated airflow (noise) passing between the vibrating folds, whose vibration may also be disturbed (frequency and amplitude perturbations), because of changes in its mechanical properties. Disruption in the positioning of the vocal folds and in timely response to muscular forces may possibly be influenced by changes in the cricoarytenoid joint (Kahn and Kahane 1986; Kahane 1988). Alterations in articular surfaces, synovial tissues and joint capsule may influence the speed and accuracy with which vocal folds can be positioned during voicing.

\section{Changes in innervation}

Altered innervation within the aging larynx and to the vocal folds (TA muscle) involves changes to both the peripheral nerves and NMJs. Kawabuchi and colleagues (2001) provide insight into normal aging alterations in NMJs from their study of reinnervation of the crushed sciatic nerve in 64 rats (30 adult and 34 aged). They have found that the processes involved in reinnervation were dramatically altered in aged rats compared to younger adult counterparts. Salient differences included alterations in their morphology of Schwann cells in aged nerves, and in their arrival at developing ACh receptor sites. The diminished influence of the Schwann cells alter the architecture of the ACh receptor sites. The outgrowth of terminal Schwann cells in aged nerves appeared
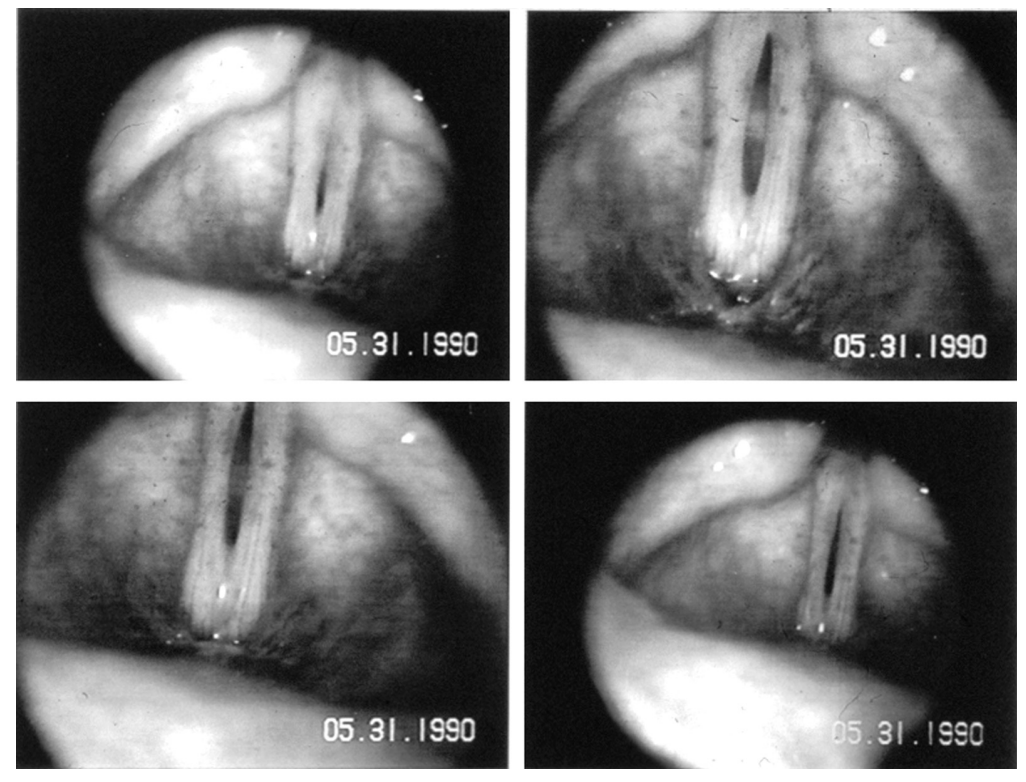

Figure 5 Endoscopic pictures of the vocal folds of a 58 year old woman during phonation, who presents with bowing of the vocal folds, thinning lamina propria and a persistent glottal chink. 
to adversely affect regenerating axons in their ability to interconnect with motor endplates. The authors suggested that reduction in trophic support for neurons may result in greater muscle atrophy following denervation.

Both superior (SLN) and recurrent laryngeal nerves (RLN) have been shown to undergo some degenerative changes with increasing age in studies where rat (Malmgren and Ringwood 1988) and human nerves (Gambino et al 1990; Mortelliti et al 1990; Périé et al 1997; Nagai et al 2005) were used. Decreased numbers of fibers have been demonstrated in SLN (Mortelliti et al 1990) and RLN (Malmgren and Ringwood 1988). Distal axonal degeneration to the intrinsic laryngeal muscles was reported by Périé et al (1997). Another study (Gambino et al 1990) brings evidence to suggest that the posterior cricoarytenoid (PCA) muscle may be more robust than other intrinsic muscles, in that NMJs showed no significant age related changes. This may, in part, be explained by the important functional role played by the PCA, as the sole muscle responsible to ensuring patency of the airway. The effects of deficiencies in laryngeal sensory innervation to motor control and muscle integrity have been discussed by Nagai et al (2005). In their study of selectively denervated rats, they found that deficits in laryngeal sensation altered the myosin heavy chain composition, which significantly influences muscle contraction time. Myosin heavy chain replacement or transformation to slower isoforms have been shown to be caused by aging and injury to the RLN (DelGaudio and Sciote 1997; Suzuki et al 2002).

The NMJ in aging laryngeal muscles appear to undergo structural changes which result in altered functioning of the vocal folds. These changes, drawn from studies of rat larynges, clearly indicate that the altered NMJ and motor end plate are related to degeneration of the RLN and attempts to reinnervate the TA muscle. Malmgren and Ringwood (1988) and Malmgren et al (1999) reported that there was a loss in motor units in the aging TA muscle, resulting from degeneration in the RLN. Further, the reconstituted NMJ were structurally deficient, having significantly reduced ACh receptor sites, variability in the architecture of the end plate (Connor et al 2002), and abnormalities in the pre-terminal and terminal regions as well as poor terminal axon morphology (Kawabuchi et al 2001). In the TA, large motor units were affected more than the smaller ones. The aging changes have been likened to those which characterize reinnervation; however they are less precise and functionally produce greater duration of response. This was not observed in human subjects younger than 60 year old (Takeda et al 2000). An additional issue worth considering in an older patient with ADSD is the relationship of reconstitution of the NMJ following BT injection with the previously noted effects of aging.

Despite the primary importance of the larynx in voice production, it would be erroneous to view it as the sole contributor to the characteristics of the aging voice. As shown in Figure 6, the peripheral speech mechanism is composed of many structures of the upper aero-digestive system, which are integrated into a highly coordinated apparatus designed to modulate air pressure and air flow. From a mechanical viewpoint, it consists of a series of valves and passageways whose geometry is transiently changed as it conditions air pressure and air flow into distinct and familiar outputs recognized as articulated speech and voice. Intrinsic changes within the larynx attributed to aging, may impact on vocal functioning by altering pitch, reducing loudness, introducing noise into the source (tonal) signal and altering voice quality.

Clearly, laryngeal aging adversely affects voice production by altering the integrity of the vocal folds resulting in reduced mechanical and metabolic capacities which affect efficiency and economy of function, as well as restorative capabilities. Ramig and Ringel (1983) have shown that physiological rather than chronological aging appears to have the greatest impact on the integrity of speech and vocal functioning. Not all organs or systems age concurrently and to the same extent. Nor are all of the typical perceptual characteristics assigned to an "older sounding voice" related to natural involution of the vocal folds (Woo et al 1992). Extralaryngeal factors may

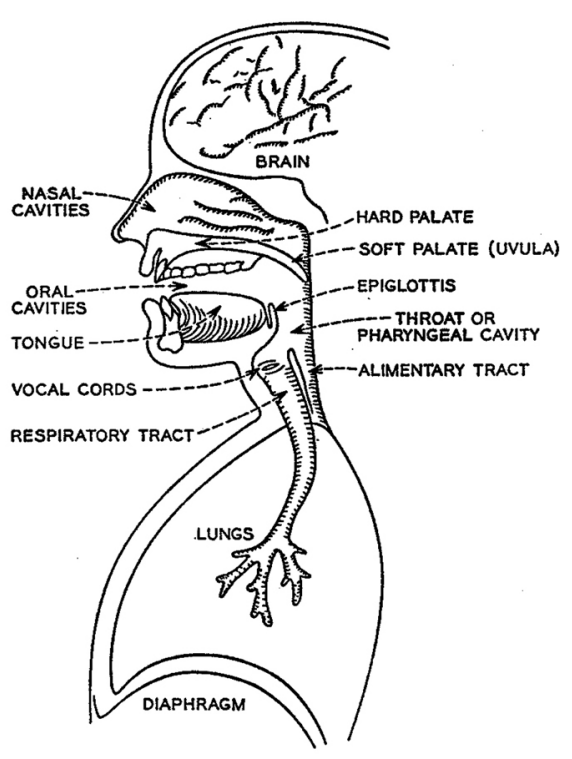

Figure 6 Diagrammatic representation of the major structures contributing to the peripheral speech mechanism. Structures of the upper and lower respiratory tracts are functionally interfaced and programmed by the CNS to produce voice and speech. 
also contribute to altered vocal functioning in the elderly and include the effects of medication, which may cause deficiencies in hydration and proprioception and by such systemic conditions as gastroesophageal reflux. Additionally, research data have shown that there are many changes in supralaryngeal cavities and structures, which contribute to the altered efficiency and perception of aging in the voice. A brief summary of these effects follows.

\section{Supralaryngeal contributions to aging voice}

In addition to the laryngeal contributions to aging of the voice, numerous reports have been published illustrating the changes within the supralaryngeal speech mechanism may affect the quality of speech production (Kahane 1981, 1990; Linville 1996). Examples include reduced precision of articulation (Hartman 1979; Amerman and Parnell 1990), difficulties in maintaining fluency under circumstances of high cognitive stress (Duchin and Mysak 1987), reduced rate of speech (Benjamin 1982; Liss et al 1990), reduction in phoneme duration for consonants and vowels (Forrest et al 1989; Morris and Brown 1987, 1994), use of greater intonation and contrastive stress (Scukanec et al 1996), perhaps as compensatory measures for speech changes noted, and formant frequency alterations. Formant frequency alterations for vowels are a measure of vocal tract resonance and stability. Though velopharyngeal function has not been shown to change significantly with aging (Hoit et al 1994), vocal tract efficiency may become decreased as resonatory capabilities are changed by hypotonicity of pharyngeal musculature, lengthening of the vocal tract, through a combination of lowering of the larynx and changes in intraoral morphology (Endres et al 1971; Xue and Hao 2003), and a tendency for speakers to adopt more restricted articulatory posturing (centralization) during vowel production.

Some normal, age related speech alterations are evident in Figure 2 (top panel), wherein the older speaker exhibits weak intensity during production of "when" as well as slight prolongation of /s/ in "sun." Vowels exhibit some stippling (aperiodic energy) in the higher frequencies, suggesting breathiness. Overall rate of syllable production is slightly slower in the older normal speaker compared to the younger normal speaker in Figure 1 (top panel).

\section{Aging and ADSD}

Untreated ADSD has not been observed to worsen with advancing age, suggesting that it is not a degenerative disorder (Aronson 1990). Brodnitz (1976) examined age of onset in 130 cases reporting an average age of 50 years, with onsets ranging from the 20 s (10 per cent) to 60 and older (18 per cent). The effect of aging upon treatment outcome in ADSD has not been well studied. Two of the primary efficacy studies, for example, did not report age data for their ADSD patient samples (Truong et al 1991; Blitzer et al 1998). BT treatment studies have reported a broad age range of ADSD. For example, Whurr et al (1993) report subjects' ages ranging from 31 to 82 years with a mean of 57 years $(\mathrm{N}=31)$, while Langveldt et al (2001) reported an age range of 32-72 years with a mean of $47(\mathrm{~N}=46)$. Neither of these studies, however, examined aging as a treatment outcome factor.

To date four studies have examined aging with respect to response to BT injection in ADSD. Ford et al (1992) first examined the correlation between age and initial BT treatment outcome and found it to be statistically non-significant. This may have been due to the fact that their subject pool consisted of patients with both ADSD and ABSD. ABSD did not respond favorably to BT injection of the vocal folds, in contrast to the significant benefit observed for those with ADSD. Computing a correlation of treatment outcome with age for all subjects combined, but not partitioning by disorder type, may have suppressed age related variance in treatment outcome for ADSD. Another factor that may have diminished the correlation was overall pre-treatment severity. Ford et al (1992) reported that overall severity strongly influenced treatment outcome, but it was not controlled in their analysis of aging. Subsequently, Lundy et al (1998) examined patient self-ratings of outcome following initial BT injection. They found that older patients rated their outcomes more poorly than younger patients. They also found, however, that greater levels of pre-injection severity of dysphonia and the presence of movement disorders elsewhere in the body also were more prevalent in the older subjects. Because these variables were, in themselves strong outcome predictors, the effect of aging on response to $\mathrm{BT}$, while significant, was felt to be somewhat confounded with overall severity of the disorder. Wingate et al (2005), examined pre-to-post BT injection change in a group of 13 older patients with ADSD, ranging in age from 65 to 77 years, who had been receiving BT injections for at least one year. Their results, based on a patient self-rating index of functional outcomes, demonstrated no statistically significant change from pre-to-post injection. Several patients, however, reported that their voices did improve.

Cannito et al (2004) directly examined the quality of speech produced by older and younger persons with ADSD using perceptual scaling judgments in a single-blind prepost treatment design. Speakers with ADSD ranged in age 
from 22 to 79 years with a mean of 53 years. The patients were evaluated before and after their initial injection of BT into the vocal folds, during a period from approximately 2.5 to 7.0 weeks post-injection. This time window was established by triangulating physiological and patient self-rating data obtained from three independent studies (Aronson et al 1993; Liu et al 1996; Fisher et al 1999) of the fine grained fluctuations in post-injection vocal function. These studies have demonstrated that glottal competence begins to recover by approximately 2 weeks (Fisher et al 1999), while vocal spasms attain maximal decrease by 2 weeks and maintain that level for an additional 42 days, on average (Liu et al 1996). As a group the patients exhibited a beneficial response to BT injection, however, there were significant variations as a function of pre-treatment severity of ADSD. The relationship of aging to magnitude of pre-to-post treatment change was also examined, with severity statistically controlled. Multiple regression analysis demonstrated that age accounted for a small but statistically significant proportion of the variance in clinical change, such that the older the individual, the smaller the postinjection improvement. It was also noted that of the nine subjects whose voices became worse following treatment, five were older than 70 years.

\section{Retrospective analysis}

To more fully appreciate the influence of aging on response to initial BT injection, a reanalysis of the (Cannito et al 2004) data was undertaken to examine the response of ADSD to initial BT injection for each of five age groups, and to compare them with age matched normal controls.

\section{Method}

Forty-two subjects with ADSD were administered BT using the transcutaneous injection procedure under EMG guidance that was previously discussed. Their demographic and clinical characteristics are presented in Table 1. ADSD speakers were grouped according to chronologic age at the pre-treatment recording. For statistical analysis, two subjects in their 20s were pooled with seven subjects in their 30 s to comprise the youngest age group. There were 8 subjects in their $40 \mathrm{~s}, 9$ subjects in their $50 \mathrm{~s}$, 9 subjects in their 60s, and 7 subjects in their 70s. ADSD participants did not exhibit movement disorders elsewhere in the body, and did not have perceptible voice tremor. The age groups did not differ significantly on the basis of injection side (ie, left, right, or both vocal folds), years post-onset of ADSD, dosage, or days post injection for second recording.
Age and gender-matched non-dysphonic controls were similarly grouped by age.

Six listeners with expertise in voice disorders and six with expertise in fluency disorders heard recordings of a standard oral reading passage obtained prior to BT injection and 3-6 weeks after injection from each of 42 speakers with ADSD, and from 42 normal controls. Recordings were presented in a fully randomized order to each listener at conversational loudness levels in a psycho-acoustically controlled environment. They responded by positioning a mouse driven cursor on a colored histogram, displayed on a computer monitor, with end points labeled very good/very poor for each of four attributes of voice or fluency depending upon the listener's area of expertise. Table 2 provides definitions of the voice and fluency attributes. Following preliminary training which gave them a common frame of reference with respect to the range of vocal behaviors to be scaled, listeners were instructed to judge each recording in terms of its deviation from their own internal standard of normalcy. Listeners were blinded as to speech sample conditions. The method yielded high levels of intra- and inter-listener reliability (See Cannito et al (2004). The mean of six judges visual analog scaling (VAS) scores for the four voice attributes and the mean of six judges VAS scores for the four fluency attributes were computed for each speaker in each condition (ADSD pre-BT, ADSD post-BT, and Control). These served as observational units for statistical analysis.

\section{Results}

Figure 7 provides age-group plots of the mean VAS scores for the individual dependent variables for voice quality (overall voice quality, roughness, brokenness, breathiness) and Figure 8 provides mean VAS scores for individual variables for fluency (overall fluency, tension struggle, vocal spasms, dysfluent syllables). Inspection of these figures indicates some variation for specific variables. All of the fluency variables as well as overall voice quality and roughness demonstrated a consistent pattern. The 70 year old group showed little or no improvement after BT injection, but substantial improvement was noted for the other age groups. Brokenness appears to have improved for all age groups; however the smallest change was evident in the 70 year old group. Breathiness showed little change in the 40 and 50 year old groups, but became worse in the 20, 60 and 70 year old groups, with the oldest speakers exhibiting the greatest amount of perceived post-treatment breathiness. 
Table I Characteristics of speakers with adductor spasmodic dysphonia

\begin{tabular}{|c|c|c|c|c|c|c|}
\hline $\begin{array}{l}\text { Age } \\
\text { years }\end{array}$ & Gender & $\begin{array}{l}\text { Initial } \\
\text { severity }\end{array}$ & $\begin{array}{l}\text { Years } \\
\text { SD }\end{array}$ & $\begin{array}{l}\text { Injection } \\
\text { type }\end{array}$ & $\begin{array}{l}\text { Dosage } \\
\text { units }\end{array}$ & $\begin{array}{l}\text { Days post } \\
\text { injection }\end{array}$ \\
\hline 22 & $F$ & Moderate & 5 & Unilateral & 2.5 & 31 \\
\hline 28 & $F$ & Mild & 3 & Unilateral & 2.5 & 36 \\
\hline 31 & $\mathrm{~F}$ & Mild & 2 & Unilateral & 5 & 31 \\
\hline 31 & $\mathrm{~F}$ & Severe & 4 & Unilateral & 15 & 45 \\
\hline 32 & $\mathrm{~F}$ & Mild & 2 & Bilateral & 5 & 32 \\
\hline 33 & $\mathrm{~F}$ & Moderate & 4 & Unilateral & 2.5 & 50 \\
\hline 38 & $F$ & Severe & 9 & Unilateral & 15 & 38 \\
\hline 38 & $\mathrm{~F}$ & Mild & 5 & Unilateral & 2.5 & 23 \\
\hline 38 & $\mathrm{~F}$ & Profound & 4 & Bilateral & 2.5 & 22 \\
\hline 41 & $\mathrm{~F}$ & Profound & 16 & Bilateral & 2.5 & 34 \\
\hline 41 & $\mathrm{~F}$ & Mild & 4 & Bilateral & 10 & 44 \\
\hline 42 & $\mathrm{~F}$ & Mild & 4 & Unilateral & 2.5 & 27 \\
\hline 42 & $M$ & Moderate & 9 & Unilateral & 7.5 & 22 \\
\hline 44 & $\mathrm{~F}$ & Mild & 7 & Unilateral & 2.5 & 22 \\
\hline 45 & $\mathrm{~F}$ & Severe & 12 & Unilateral & 15 & 45 \\
\hline 46 & $\mathrm{~F}$ & Moderate & 9 & Unilateral & 15 & 34 \\
\hline 46 & $F$ & Severe & 9 & Bilateral & 2.5 & 43 \\
\hline 51 & $M$ & Severe & 4 & Unilateral & 30 & 29 \\
\hline 51 & $\mathrm{~F}$ & Severe & I & Unilateral & 5 & 36 \\
\hline 52 & $\mathrm{~F}$ & Mild & 19 & Bilateral & 1.5 & 34 \\
\hline 52 & $\mathrm{~F}$ & Moderate & 24 & Unilateral & 5 & 35 \\
\hline 54 & $\mathrm{~F}$ & Profound & 4 & Bilateral & 2.5 & 30 \\
\hline 54 & $M$ & Moderate & 9 & Unilateral & 7.5 & 27 \\
\hline 56 & $\mathrm{~F}$ & Profound & 16 & Unilateral & 30 & 34 \\
\hline 56 & $\mathrm{~F}$ & Moderate & 13 & Unilateral & 15 & 31 \\
\hline 57 & $\mathrm{~F}$ & Profound & 14 & Bilateral & 2.5 & 38 \\
\hline 60 & $\mathrm{~F}$ & Severe & 6 & Unilateral & 15 & 37 \\
\hline 61 & $\mathrm{~F}$ & Profound & 9 & Bilateral & 5 & 31 \\
\hline 63 & $\mathrm{~F}$ & Moderate & II & Unilateral & 15 & 31 \\
\hline 63 & $\mathrm{~F}$ & Severe & 9 & Bilateral & 5 & 17 \\
\hline 64 & $\mathrm{~F}$ & Profound & 10 & Unilateral & 15 & 29 \\
\hline 64 & $\mathrm{~F}$ & Profound & 11 & Bilateral & 2.5 & 27 \\
\hline 64 & $\mathrm{~F}$ & Mild & 10 & Unilateral & 1.25 & 27 \\
\hline 67 & $\mathrm{~F}$ & Profound & 13 & Bilateral & 2.5 & 51 \\
\hline 67 & $M$ & Moderate & 8 & Bilateral & 5 & 20 \\
\hline 70 & $\mathrm{~F}$ & Severe & 5 & Unilateral & 5 & 48 \\
\hline 71 & $\mathrm{~F}$ & Mild & 20 & Unilateral & 7.5 & 29 \\
\hline 71 & $M$ & Severe & 19 & Bilateral & 5 & 36 \\
\hline 72 & $\mathrm{~F}$ & Severe & 8 & Unilateral & 7.5 & 42 \\
\hline 74 & $\mathrm{~F}$ & Severe & 9 & Bilateral & 2.5 & 36 \\
\hline 77 & $\mathrm{~F}$ & Severe & 8 & Unilateral & 5 & 27 \\
\hline 79 & $M$ & Mild & 5 & Unilateral & 5 & 36 \\
\hline
\end{tabular}

VAS data were submitted to a mixed-effects repeated measure, multivariate analysis of covariance (MANCOVA). Age group was the between subjects variable, and speaking condition (pre-BT ADSD, post-BT ADSD, Control) was the within subject variable or repeated measure. There were four dependent variables for voice (overall voice quality, roughness, breathiness, brokenness) and four dependent variables for fluency (overall fluency, tension struggle, vocal spasms, and disfluent syllables). Pre-BT severity of
ADSD served as the covariate in order to remove variance attributable to this known confounding variable, which was not uniformly distributed across the age range. Sex was treated as blocking variable in order to partition its variance, due to the small number of male subjects $(n=6)$ in the data set.

MANCOVA results demonstrated that there was a statistically significant main effect of age group $(p=0.019)$, as well as a significant interaction of speaking condition by 
Table 2 Attributes of voice and fluency for perceptual scaling experiments

\begin{tabular}{|c|c|c|}
\hline Attribute & Description & End points \\
\hline \multicolumn{3}{|c|}{ Voice scaling experiment } \\
\hline Overall voice quality & $\begin{array}{l}\text { A general perceptual impression of an } \\
\text { appropriate degree of melodiousness } \\
\text { periodicity, and richness of the tonal } \\
\text { components of the voice exhibited across } \\
\text { the speech sample }\end{array}$ & $\begin{array}{l}\text { Extremely good/ } \\
\text { Extremely poor }\end{array}$ \\
\hline Breathiness & $\begin{array}{l}\text { Audible occurrence of breath noise or } \\
\text { acoustic turbulence in the voice signal } \\
\text { perceived either as "whispery" or } \\
\text { "murmured" quality across the speech } \\
\text { sample }\end{array}$ & Absent/Pervasive \\
\hline Roughness & $\begin{array}{l}\text { Audible occurrence of acoustic aperiodicity } \\
\text { in the voice signal perceived as either } \\
\text { "harsh," "gruff" or "strained-strangled" } \\
\text { quality across the speech sample. }\end{array}$ & Absent/Pervasive \\
\hline Brokenness & $\begin{array}{l}\text { Audible occurrence of the unexpected } \\
\text { momentary absence of the voicing signal } \\
\text { perceived as "gaps" or "cracks" in voicing } \\
\text { across the speech sample }\end{array}$ & Absent/Pervasive \\
\hline \multicolumn{3}{|c|}{ Fluency scaling experiment } \\
\hline Overall fluency & $\begin{array}{l}\text { A general perceptual impression of the } \\
\text { prompt, smooth, easy and continuous } \\
\text { forward flow of speech exhibited across the } \\
\text { sample. }\end{array}$ & $\begin{array}{l}\text { Extremely good/ } \\
\text { Extremely poor }\end{array}$ \\
\hline Tension struggle & $\begin{array}{l}\text { Perceived occurrence of audible effort, } \\
\text { hesitation and straining to initiate or } \\
\text { maintain the forward flow of speech across } \\
\text { the sample. }\end{array}$ & Absent/Pervasive \\
\hline Disfluent syllables & $\begin{array}{l}\text { Perceived occurrence of inappropriate } \\
\text { syllables that are repeated, added, or } \\
\text { prolonged within the ongoing flow of } \\
\text { speech across the sample. }\end{array}$ & Absent/Pervasive \\
\hline Vocal spasms & $\begin{array}{l}\text { Perceived occurrence of quavering, } \\
\text { squeezing or stoppage of the voice } \\
\text { sufficient to disrupt the ongoing flow of } \\
\text { speech across the sample }\end{array}$ & Absent/Pervasive \\
\hline
\end{tabular}

Reprinted with permission from Cannito MP, Woodson GE, Murry T, et al. 2004. Perceptual analyses of spasmodic dysphonia before and after treatment. Arch Otolaryngol Head Neck Surg, 130:1393-9. Copyright ๑ (2004), American Medical Association. All rights reserved.

age group $(\mathrm{p}=0.006)$ with pre-treatment severity controlled. Given the absence of significant interactions involving individual variables, and in the interest of simplification, voice and fluency composite scores were computed. Means and standard deviations are provided by age group for each perceptual composite score based on the voice and fluency attributes in Table 3. These represent aggregates of the four rated attributes of voice and of fluency, and reflect mean listener judgments of the overall goodness of the speakers' voice and fluency.

Figures 9 and 10 depict the significant age by treatment interaction effect for voice (Figure 9) and for fluency (Figure 10). Post hoc means comparisons demonstrated that there were statistically significant differences $(p<0.05)$ between all ADSD age groups and their age-matched control samples before and after BT injection. All ADSD age groups demonstrated statistically significant improvement from preto-post BT injection $(\mathrm{p}<0.05)$, with the exception of the 70-79-year-old group, who exhibited little change following treatment. A precipitous decline in post treatment mean scores exhibited by the oldest ADSD group also is evident in Figures 9 and 10. In addition, the 70-79-year-old normal controls differed significantly from the other control subject age groups, who did not differ from each other. Figures 9 and 10 also demonstrate the decline in voice quality and fluency exhibited by the oldest control age group. While some attenuation of voice quality was evident in the 60-69 year old group, it did not attain statistical significance $(\mathrm{p}=0.13)$. 

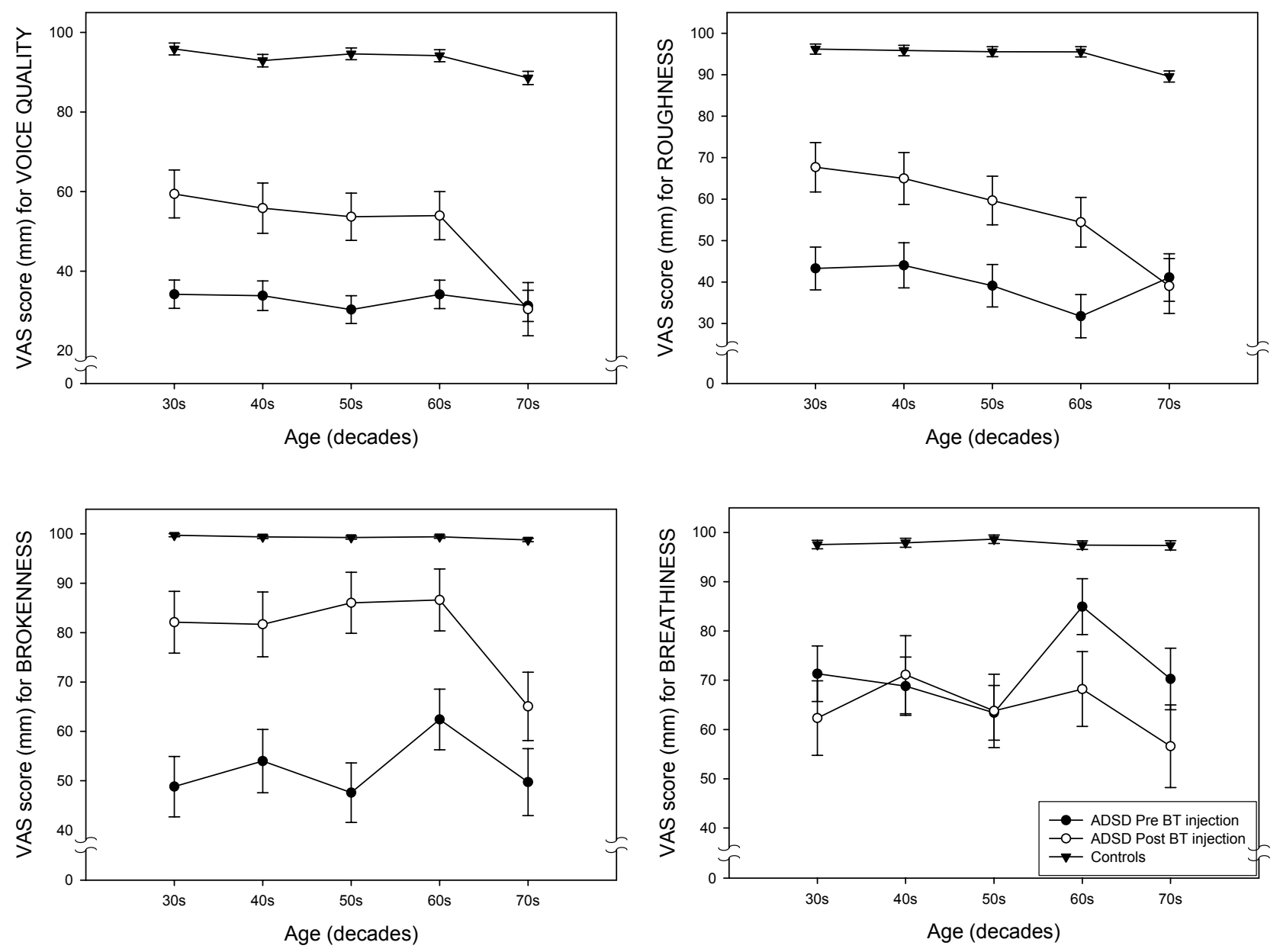

Figure 7 Age-group plots of the means and standard deviations of visual analog scaling (VAS) scores for the four voice attributes (overall voice quality, roughness, brokenness, breathiness).

A number of potentially confounding variables were free to vary in the present study, due to the retrospective nature of the sample, which one might argue could account for apparent age-related findings. Specifically, dosage units for BT administration, site of injection (ie, unilateral vs. bilateral TA muscles), and number of days post injection until audio recording. It is possible that age-biased distribution of these variables may have introduced variability that contributed to the observed results, if in fact these variables could be shown to have a significant impact on the present speakers response to BT. Analyses were conducted to examine the influence of these potential confounds in the present data set. Table 4 provides mean values for these variables by age group.

Dosage levels for the oldest group were in the midrange of total units (2.5-7.5 units) and were comparable to that of the youngest group. The single lowest dosage of 1.25 units occurred in the 60 year olds, while the 50 year olds included two cases who received the highest dosages of 30 units. Yet both of these groups showed substantial benefit. Age group means for days post injection varied from 30 (for 60 year olds) to 36.29 (for 70 year olds). Univariate ANOVAs for dosage and days post injection did not differ significantly across the age groups $(p>0.10)$. Site of injection varied from 7 unilateral injections in the 30 year olds, to 4 unilateral injections in the 60 year olds, whereas the 30 year old and 70 year old group each included two bilateral injections. Chi-square analysis demonstrated no significant difference $(p=0.654)$ in the distribution of unilateral versus bilateral injection on the basis of age group. Taken individually, there were no significant correlations $(p>0.10)$ of these variables with age or with response to BT (defined as the pre-to-post injection difference score). Multiple regression analysis also demonstrated that a linear combination of these variables was not significantly predictive of response to BT $(p>0.10)$, nor was it predictive of age $(\mathrm{p}>0.10)$. 

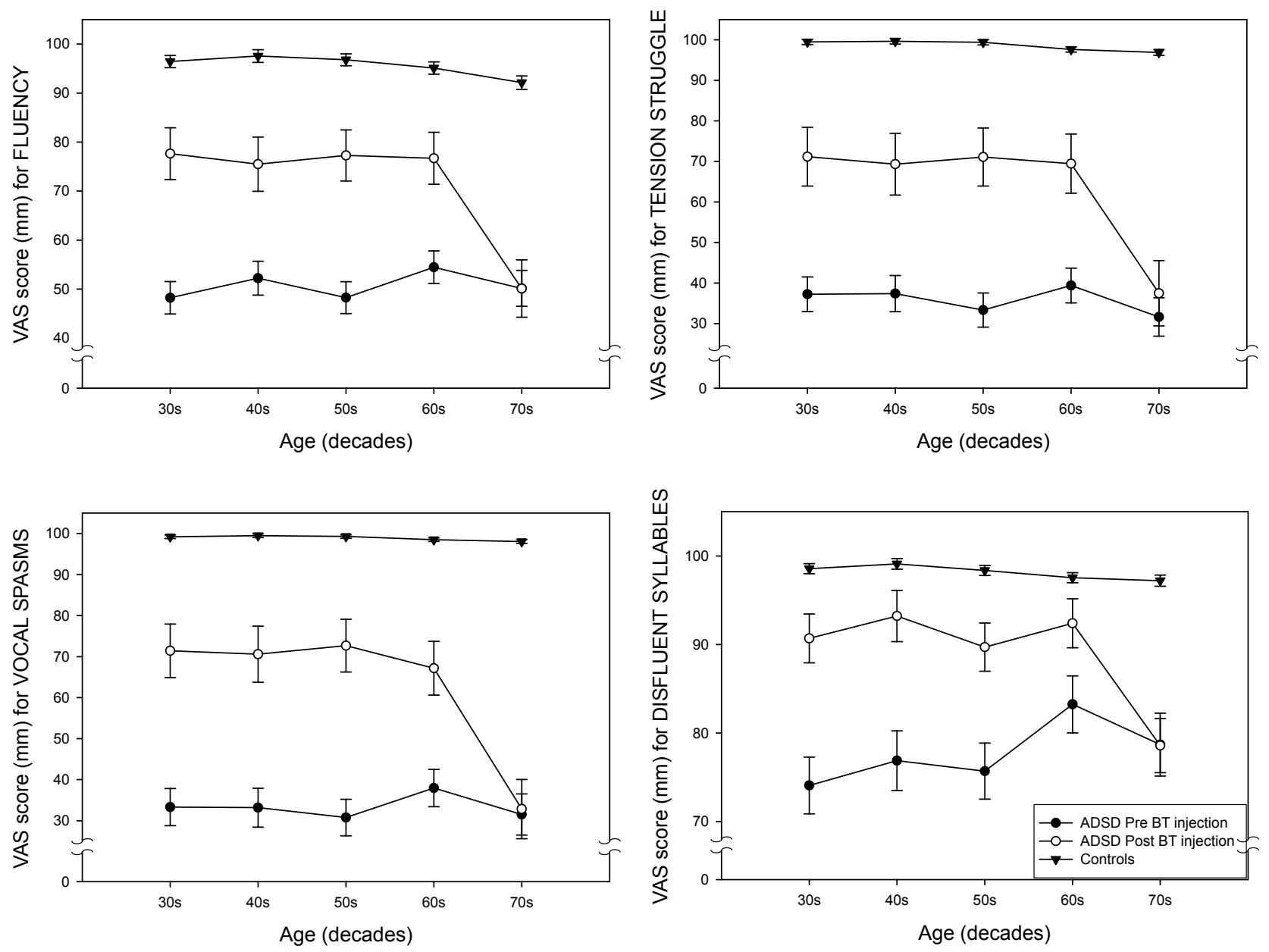

Figure 8 Age-group plots of the means and standard deviations of visual analog scaling (VAS) scores for the four fluency attributes (overall fluency, tension struggle, vocal spasms, dysfluent syllables).

\section{Conclusions}

The present analysis demonstrates a number of interesting findings. First, the oldest controls, while still performing within a relatively normal range of perceived voice quality (ie, significantly better than the disordered groups), were perceived to have poorer voice and fluency than their younger counterparts. This is consistent with expectations regarding aging of the larynx and speech mechanism. Second, untreated ADSD was not perceived to deteriorate as a function of age. There were no significant differences between younger and older age groups prior to treatment. This is consistent with prior studies (Aronson et al 1993; Brodnitz 1976). Third, following treatment there was a substantial improvement for all age groups with ADSD except the 70-79 year olds. As it is evident in Figures 9 and 10, the distribution of ADSD mean scores, even after treatment, occurs in a distinctly different range of perceived vocal/fluency function than that of normal controls. It is therefore likely that the perceptual salience of
ADSD overrides and obscures the more subtle effects of normal vocal aging, such as that exhibited by the older controls. Following treatment, aging voice alone could have accounted for only a small percentage of the perceived severity of the oldest ADSD group. It remains possible, however, that sensitive physiological studies (eg, air flow and air pressure measures) may be able to demonstrate some age related differences in untreated ADSD. Third, the oldest ADSD subjects studied (70-79-year-olds) did not exhibit expected improvement in response to BT injection of the vocal folds. This was not a gradual shift in response over the age range, but rather an abrupt change demonstrated only in the oldest group. The facts that they did not demonstrate merely an attenuation of improvement following treatment, in comparison with the other age groups, and that several of these older speakers actually worsened after BT injection, strongly suggest that there may indeed be a physiological interaction between aging laryngeal tissues and BT injection. 
Table 3 Means and standard deviations of composite scores for voice, fluency, and overall scores are shown for three groups: controls, ADSD subjects before and after BT injection by age group*

\begin{tabular}{|c|c|c|c|c|c|c|}
\hline \multirow[t]{2}{*}{ Decades } & \multicolumn{2}{|c|}{ Composite voice } & \multicolumn{2}{|c|}{ Composite fluency } & \multicolumn{2}{|c|}{ Composite overall } \\
\hline & Mean & $\overline{\text { SD }}$ & Mean & $\overline{\text { SD }}$ & Mean & SD \\
\hline \multicolumn{7}{|c|}{ Non-dysphonic controls } \\
\hline 30 & 97.51 & 1.67 & 98.57 & 1.72 & 98.04 & 1.61 \\
\hline 40 & 96.65 & 2.47 & 99.06 & 0.54 & 97.85 & 1.34 \\
\hline 50 & 96.90 & 1.19 & 98.36 & 0.91 & 97.63 & 0.73 \\
\hline 60 & 96.43 & 1.83 & 97.03 & 2.54 & 96.73 & 2.10 \\
\hline 70 & 93.59 & 3.72 & 96.08 & 2.72 & 94.84 & 2.62 \\
\hline \multicolumn{7}{|c|}{ Pre BT injection } \\
\hline 30 & 57.31 & 24.99 & 58.18 & 26.80 & 57.74 & 25.72 \\
\hline 40 & 55.99 & 23.05 & 57.26 & 27.06 & 56.62 & 24.93 \\
\hline 50 & 40.09 & 18.85 & 40.71 & 20.68 & 40.40 & 19.61 \\
\hline 60 & 44.61 & 13.29 & 42.81 & 22.74 & 43.71 & 17.92 \\
\hline 70 & 48.88 & 20.46 & 48.99 & 24.0 & 48.93 & 22.05 \\
\hline \multicolumn{7}{|c|}{ Post BT injection } \\
\hline 30 & 70.75 & 15.19 & 81.85 & 15.92 & 76.30 & 15.12 \\
\hline 40 & 70.52 & 15.78 & 80.19 & 17.27 & 75.35 & 16.12 \\
\hline 50 & 63.97 & 16.65 & 75.07 & 22.19 & 69.52 & 19.20 \\
\hline 60 & 62.64 & 12.81 & 71.90 & 13.42 & 67.27 & 12.26 \\
\hline 70 & 48.07 & 14.56 & 50.17 & 18.14 & 49.12 & 16.14 \\
\hline
\end{tabular}

*Values adjusted for the covariates of severity and gender.

\section{General discussion}

Botox therapy is the method of choice for treating ADSD. The effects of aging on BT treatment effectiveness are not well understood or documented. Ford et al (1992) have suggested that age does not influence the effectiveness of BT treatment of ADSD. This is a striking finding, given the results of others who showed that physiological aging and health status (Ramig and Ringel 1983) and systemic conditions affecting the aged, such as atherosclerosis (Orlikoff 1990), contributed significantly to vocal instability and depreciated voice quality, when analyzed with regard to the performance of all younger cohorts studied. In both studies, the authors reported that poorer voice production was observed in the oldest age groups (subjects older than age 60). This corresponds well with the oldest group in our study. It also appears to support the notion that there is a critical period when the aggregate of the involutional changes begin to be reflected in perceived differences in normal vocal functioning (Kahane 1990; Linville 1996).

Evidence from the current study showed that voices of older normal subjects differed significantly from older ADSD counterparts. This underscored the fact that vocal instability and alteration in speech flow in normal aging is different from that observed in older ADSD subjects. Not only were the oldest ADSD voices quantitatively different from all other subjects post injection, they were perceived as having the poorest voice quality of all the ADSD subjects.
These findings suggest that in both normal and ADSD aged speakers, age related intrinsic changes in the vocal folds and vocal tract alter the physiological capabilities of the phonatory mechanism. However, the ADSD subjects have the addition of a focal dystonia superimposed upon normal involutional changes within the larynx. It thus appears that BT injection is not able to reconstitute the vocal mechanism of these older ADSD voices to expected levels of functioning, though these are inherently mechanically less efficient than younger mechanisms. In the present study, however, these normal aging changes were not sufficient to account for the depressed treatment outcomes of the older ADSD speakers.

Of particular relevance to the poorer quality of voice and fluency of older speakers with ADSD after BT injection, is the possibility that the older vocal folds respond less effectively to BT therapy for several reasons. These include:

1. Degenerative changes in the SLN and RLN (Malmgren and Ringwood 1988; Mortelliti et al 1990) and resulting regressive changes in the vocalis muscle of the vocal folds (DelGaudio and Sciote 1997; Périé et al 1997; Suzuki et al 2002).

2. Loss of motor units in the TA muscles, resulting from degeneration in the recurrent laryngeal nerve fibers (Malmgren and Ringwood 1988; Mortelliti et al 1990). Functional decline in the vocal fold musculature in ADSD reported from EMG studies by (Davidson and Ludlow 1996), may be reflecting these changes. 


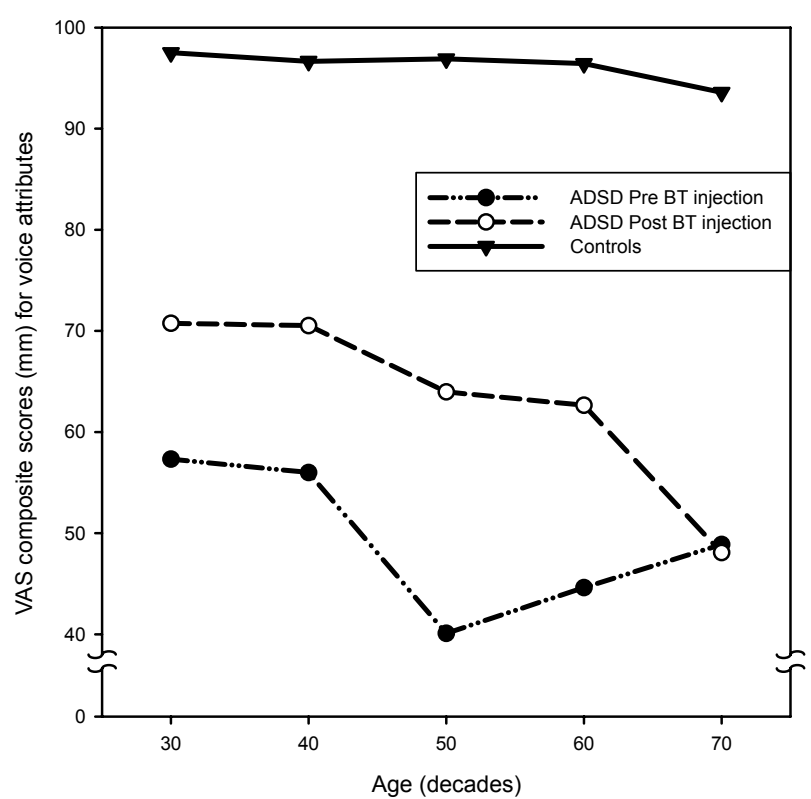

Figure 9 Interaction plots of decade by treatment condition for mean composite scores for voice for three groups: non-dysphonic controls, ADSD before BT injection and the same ADSD subjects after BT injection.

3. Structural abnormalities in ACh receptor site architecture as seen in the aging rat vocal folds (Connor et al 2002).

4. TA muscle atrophy and associated connective tissue changes within the vocal folds, may alter the geometry of the muscle so as to compromise the location of the choice injection site - center of muscle - the region of highly concentrated motor endplates (Shaari et al 1991). Thus, despite the most exacting technique, the clinician may achieve a less than maximal result, due to the altered nature of the vocal fold musculature.

5. Poorer localization of the Botox within the musculature of the vocal fold (unwanted spread from injection sites) because of hampered diffusion resulting from changes in the interstitial ground substance (Thibeault et al 2002) and altered architecture of connective tissues within the TA muscle (Kahane 1987; Shaari et al 1991). This view-

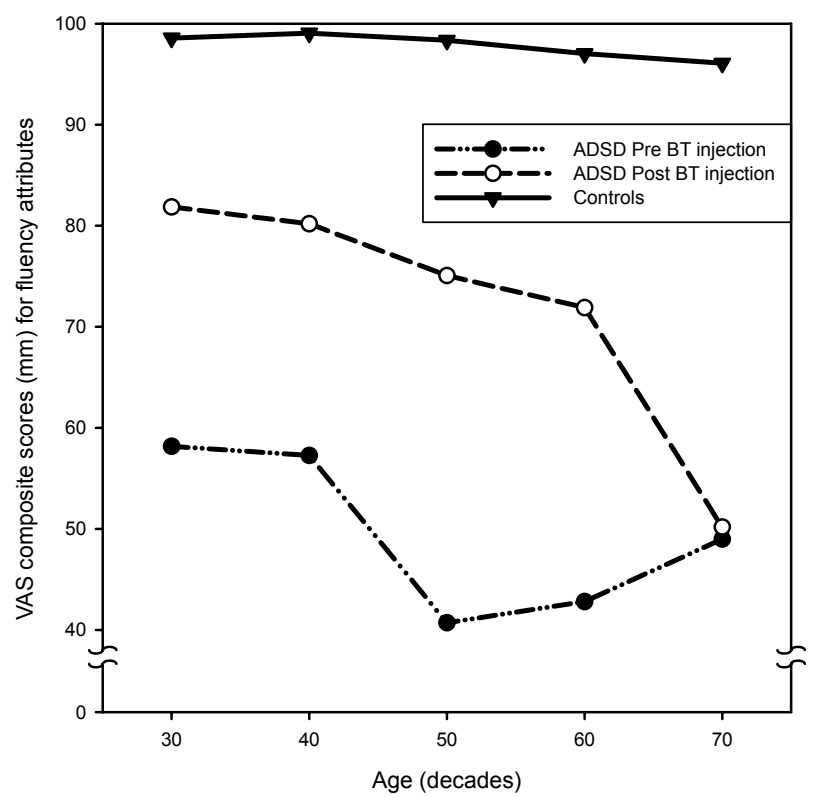

Figure 10 Interaction plots of decade by treatment condition for mean fluency composite scores by decade for three groups: non-dysphonic controls, ADSD before $\mathrm{BT}$ injection and the same ADSD subjects after BT injection.

point is supported by concerns regarding injection of the orbicularis oculi, for blepharospasm, where fibrosis and atrophy have been noted in humans treated with repeated BT injection (Assessment: the clinical usefulness of botulinum toxin-A in treating neurologic disorders. Report of Therapeutics and Technology Assessment Subcommittee of the American Academy of Neurology 1990).

Though normal aging appears to prompt several natural involutional changes in the vocal folds, changes in its neuromotor integrity may be the most significant feature in destabilizing the vocal folds and voicing of individuals with ADSD. This situation appears to become further compromised by the effects of BT injection. The recovering voice of the aged speaker may benefit form BT less than younger counterparts, because the very motor units, targeted

Table 4 Treatment characteristics for five age groups of ADSD

\begin{tabular}{llllll}
\hline Decade & N & $\begin{array}{l}\text { Mean dosage } \\
\text { (Total Units) }\end{array}$ & $\begin{array}{l}\text { Mean } \\
\text { days post } \\
\text { injection }\end{array}$ & $\begin{array}{l}\text { Type of } \\
\text { injection } \\
\text { No. Unilat }\end{array}$ & $\begin{array}{l}\text { Type of } \\
\text { injection } \\
\text { No. Bilat }\end{array}$ \\
\hline 30 year olds* & 9 & 5.83 & 34.22 & 7 & 2 \\
40 year olds & 8 & 7.19 & 33.88 & 5 & 3 \\
50 year olds & 9 & 11.00 & 32.67 & 6 & 3 \\
60 year olds & 9 & 7.36 & 30.00 & 4 & 5 \\
70 year olds & 7 & 5.36 & 36.29 & 5 & 2
\end{tabular}

*Two 20-year-olds were included in this group for statistical analysis. 
in treatment, are biologically less robust and may be less able to regenerate (fully or normally) because of deficient structural and atrophic properties. It may be prudent to temper expectations for significantly improved voice in older ADSD speakers, because their vocal mechanism is inherently less capable of reconstituting itself.

In both normal and ADSD older voices, vocal changes result from such conditions as: (1) altered patterns of vocal fold vibration; (2) reduced responsiveness of the vocal folds to subglottic pressure because of their decreased viscoelastic properties; (3) reduction in vocal control mechanisms because of vocal fold muscle atrophy which affects the efficiency of transiently changing the physical properties of the vocal folds (length, tension, mass/unit area), overcoming incomplete glottal closure (bowing); and (4) reduced efficiency of transmission of the glottal (source) signal through the vocal tract because of decreased tonicity of the pharyngeal walls and reduced efficiency of articulatory valving.

Depreciated voice quality in the older ADSD subjects after BT treatment also may have been influenced by frequently used medications, such as diuretics prescribed for such conditions as control of high blood pressure, cardiac, urologic or renal problems. These are, of course, often experienced by older people. Additionally, medications such as bronchodialators for temporizing symptoms of asthma or those related to interstitial lung disorders, may adversely affect voice quality by drying the vocal fold mucosa and reducing proprioceptive feedback. These variables were not monitored in the current study and remain a subject for further research.

Another contributing factor to poor voice quality in the older ADSD subjects may be increased anxiety and feelings of frailty and vulnerability, which have been heightened by their disabled communication and discomfort created by laryngeal spasms and respiratory compromise resulting from it. These feelings may become reinforced by the initially weak voice following BT injection, and the failure to attain normal voice production after treatment. Psychosocial responses in older ADSD subjects should be examined in future studies.

It should be remembered that in the present study, all of the ADSD patients were initial injectees. Because BT treatment is ongoing, it is possible that long term response to the treatment across multiple injections may vary from those demonstrated after initial injection. On the one hand, it is possible that older voices may improve with long term treatment. This may result from ongoing modification of dosage and injection site (Blitzer et al 1998) or from a long-term improving trend that has been noted in some longitudinal BT studies, the mechanism of which remains unclear (Mehta et al 2001; Salvatore et al 2007). Long-term improvement may explain the discrepancy in self-report by older patients with ADSD exhibited between (Lundy et al 1998), who examined initial injectees, versus (Wingate et al 2005) who examined patients who had undergone multiple injections. On the other hand, it is possible that older ADSD voices may deteriorate even further with long term botulinum toxin treatment. There is potential for increased tendency to develop immunological response by building up of antibodies to BT. Though this has been shown to occur in about $3 \%$ of BT users who were injected for more traditional use in facial cosmetic applications (Zuber et al 1993). To the best of our knowledge, no data are available about antibody production in the elderly as a treatment group or in the larynx as a target organ for BT. Further longitudinal study across repeated injections is needed to address this issue.

Although the age related findings in the present retrospective study could not be explained away on the basis of potentially confounding factors such as dosage, injection site, or days post injection at recording, these remain significant clinical variables that should be more systematically controlled in a future prospective replication. This will be particularly important for longitudinal research, wherein there is typically some degree of "trial and error" modification of dosage and injection site during ongoing re-injections. A more narrow time widow for post injection recordings or use of multiple time windows will also be desirable to minimize variability due to inter-individual recovery rates.

Finally, the limitations of perceptual voice analysis should be recognized. The final output that is radiated from the oral cavity of a speaker reflects a variety of laryngeal and supralaryngeal sources and mechanisms. Moreover, even relatively reliable expert listeners bring a certain degree or subjectivity and uncertainty to the listening experience. Thus it is possible that other measures, including acoustic, physiological and patient self-rating instruments may reveal changes in older patients with ADSD that were not captured by the perceptual methods, however rigorous, employed in the present study. Future studies comparing older and younger speakers with ADSD and their response to BT treatment should include a combination of perceptual, acoustic, physiological (eg, laryngeal resistance and airflow measures), in conjunction with patient self-reports. 


\section{Acknowledgment}

The authors gratefully acknowledge Gayle E Woodson, MD and Thomas Murry, $\mathrm{PhD}$ for providing patient recordings for this research. The data set reanalyzed in this study was originally published in Cannito, M, Woodson, GE, Murry, T, and Bender, B (2004). "Perceptual analyses of adductor spasmodic dysphonia before and after treatment." Arch Otolaryngol Head Neck Surg, 130 (12):1393-9, Copyright * 2004, American Medical Association. All rights reserved. The original research was supported by a grant from the National Institutes of Health (NIDCD Grant 1-R15-DC/OD02299-01A1).

\section{References}

Ali SO, Thomassen M, Schulz GM, et al. 2006. Alterations in CNS activity induced by botulinum toxin treatment in spasmodic dysphonia: an H215O PET study. $J$ Speech Lang Hear Res, 49:1127-46.

Amerman JD, Parnell MM. 1990. Auditory impressions of the speech of normal elderly adults. Br J Disord Commun, 25:35-43.

Aronson AE. 1990. Clinical voice disorders. 3 edition edn, New York: Thieme Medical Publishers.

Aronson AE, McCaffrey TV, Litchey WJ, et al. 1993. Botulinum toxin injection for adductor spasmodic dysphonia: Patient self-ratingof voice and phonatory effort after three successive injections. Laryngoscope, 103:683-91.

Assessment: the clinical usefulness of botulinum toxin-A in treating neurologic disorders. Report of Therapeutics and Technology Assessment Subcommittee of the American Academy of Neurology. 1990

Bach AC, Lederer FL, Dinolt R. 1942. Senile changes in the laryngeal musculature. AMA Archives of Otolaryngology, 47-56.

Benjamin BJ. 1982. Phonological performance in gerontological speech. $J$ Psycholinguist Res, 11:159-67.

Blitzer A, Brin MF. 1992. The dystonic larynx. Journal of Voice, 6:294-7.

Blitzer A, Brin MF. 1992. Treatment of spasmodic dysphonia (laryngeal dystonia) with local injections of botulinum toxin. Journal of Voice, 6:365-9.

Blitzer A, Brin MF, Stewart CF. 1998. Botulinum toxin management of spasmodic dysphonia (laryngeal dystonia): a 12-year experience in more than 900 patients. Laryngoscope, 108:1435-41.

Boutsen F, Cannito MP, Taylor M, et al. 2002. Botox treatment in adductor spasmodic dysphonia: a meta-analysis. J Speech Lang Hear Res, 45:469-81.

Brodnitz FS. 1976. Spastic dysphonia. Ann Otol Rhinol Laryngol, $85: 210-4$.

Cannito MP, Woodson GE. 2000. The Spasmodic Dysphonias. In: Kent RD, Ball MJ eds. Voice quality measurement. San Diego: Singular Publishing Group. p. 411-30.

Cannito MP, Woodson GE, Murry T, et al. 2004. Perceptual analyses of spasmodic dysphonia before and after treatment. Arch Otolaryngol Head Neck Surg, 130:1393-9.

Carnevalle-Ricci R. 1937. Osservazioni isopatologiche sulla laringe nella senescenza. Archivo Italiano di Otologi, Rhinologia e Laringologia, 49.

Connor NP, Suzuki T, Lee K, et al. 2002. Neuromuscular junction changes in aged rat thyroarytenoid muscle. Ann Otol Rhinol Laryngol, 111:579-86.

Davidson BJ, Ludlow CL. 1996. Long-term effects of botulinum toxin injections in spasmodic dysphonia. Ann Otol Rhinol Laryngol, 105:33-42.

de Paiva A, Meunier FA, Molgo J, et al. 1999. Functional repair of motor endplates after botulinum neurotoxin type A poisoning: biphasic switch of synaptic activity between nerve sprouts and their parent terminals Proc Natl Acad Sci USA, 96:3200-5.
DelGaudio JM, Sciote JJ. 1997. Changes in myosin expression in denervated laryngeal muscle. Ann Otol Rhinol Laryngol, 106:1076-81.

Devous MD Sr, Pool KD, Finitzo T, et al. 1990. Evidence for cortical dysfunction in spasmodic dysphonia: regional cerebral blood flow and quantitative electrophysiology. Brain Lang, 39:331-44.

Duchen LW. 1970. Changes in motor innervation and cholinesterase localization induced by botulinum toxin in skeletal muscle of the mouse: differences between fast and slow muscles. J Neurol Neurosurg Psychiatry, 33:40-54.

Duchen LW. 1972. Motor nerve growth induced by botulinum toxin as a regenerative phenomenon. Proc R Soc Med, 65:196-7.

Duchin SW, Mysak ED. 1987. Disfluency and rate characteristics of young adult, middle-aged, and older males. J Commun Disord, 20:245-57.

Duxson MJ, Vrbová G. 1985. Inhibition of acetylcholinesterase accelerates axon terminal withdrawal at the developing rat neuromuscular junction. J Neurocytol, 14:337-63.

Endres W, Bambach W, Flosser G. 1971. Voice spectrograms as a function of age, voice disguise, and voice imitation. J Acoust Soc Am, 49:1842-8.

Ferreri G. 1959. Senescence of the Larynx. Italian General Review of Otorhinolaryngology, 1:640-706.

Finitzo T, Freeman FJ. 1989. Spasmodic dysphonia, whether and where: results of seven years of research. Journal of Speech and Hearing Research, 32:541-55.

Fisher KV, Scherer RC, Swank PR, et al. 1999. Electroglottographic tracking of phonatory response to botox. Journal of Voice, 13:203-18.

Ford CN, Bless DM, Patel NY. 1992. Botulimun toxin treatment of spasmodic dysphonia: Techniques, indications, efficacy. Journal of Voice, 6:370-6.

Ford CN, Bless DM, Ptel NY. 1992. Botulimun toxin treatment of spasmodic dysphonia: Techniques, indications, efficacy. Journal of Voice, 6:370-6.

Forrest K, Weismer G, Turner GS. 1989. Kinematic, acoustic, and perceptual analyses of connected speech produced by parkinsonian and normal geriatric adults. $J$ Acoust Soc Am, 85:2608-22.

Gambino DR, Malmgren LT, Gacek RR. 1990. Age-related changes in the neuromuscular junctions in the human posterior cricoarytenoid muscles: a quantitative study. Laryngoscope, 100:262-8.

Gracco C, Kahane JC. 1989. Age related changes in the vestibular folds of the human larynx. A histomorphometric study. Journal of Voice, 3:204-12.

Gray SD, Titze IR, Chan R, et al. 1999. Vocal fold proteoglycans and their influence on biomechanics. Laryngoscope, 109:845-54.

Hambleton D. 1993. Therapeutic application of botulinum toxin. J Med Microbiol, 39:243-5.

Hartman DE. 1979. The perceptual identity and characteristics of aging in normal male adult speakers. J Commun Disord, 12:53-61.

Haslinger B, Erhard P, Dresel C, et al. 2005. "Silent event-related" fMRI reveals reduced sensorimotor activation in laryngeal dystonia. Neurology, 65:1562-9.

Hirano M, Sato K, Nakashima T. 2000. Fibroblasts in geriatric vocal fold mucosa. Acta Otolaryngol, 120:336-40.

Hoit JD, Watson PJ, Hixon KE, et al. 1994. Age and velopharyngeal function during speech production. J Speech Hear Res, 37:295-302.

Hommerich KW. 1972. Der Alternde Larynx: Morphologische Aspekte. Hals Nasen Ohrenaerzte, 20:115-20.

Honjo I, Isshiki N. 1980. Laryngoscopic and voice characteristics of aged persons. Arch Otolaryngol, 106:149-50.

Kahane JC. 1981. Anatomic and physiologic changes in the aging peripheral speech mechanism. In: Beasley DS, Davis GA eds. Aging: communication process and disorders. New York: Grune and Stratton. p. $21-45$.

Kahane JC. 1987. Connective tissue changes in the larynx and their effects on voice. Journal of Voice, 1:27-30.

Kahane JC. 1988. Age related changes in the human cricoarytenoid joint. In: O Fujimura ed. Vocal physiology: Voice production, mechanisms, and functions. New York: Raven Press. pp. 145-57. 
Kahane JC. 1990. Age-related changes in the peripheral speech mechanism: Structural and physiological changes, paper presented to Research Symposium on Communication Sciences and Disorders and Aging. Rockville, MD.

Kahane JC. 1996. Life span changes in the larynx: an anatomical perspective. In: WSJR Brown, BP Vinson and MA Crary eds. Organic Voice Disorders: assessment and treatment. San Diego: Singular. pp. 89-111.

Kahn AR, Kahane JC. 1986. India ink pinprick assessment of age-related changes in the cricoarytenoid joint (CAJ) articular surfaces. $J$ Speech Hear Res, 29:536-43.

Kawabuchi M, Zhou CJ, Wang S, et al. 2001. The spatiotemporal relationship among Schwann cells, axons and postsynaptic acetylcholine receptor regions during muscle reinnervation in aged rats. Anat Rec, 264:183-202.

Kersing W, Jennekens FG. 2004. Age-related changes in human thyroarytenoid muscles: a histological and histochemical study. Eur Arch Otorhinolaryngol, 261:386-92.

Knutsson E, Martensson A, Martensson B. 1969. The normal electromyogram in human vocal muscles. Acta Otolaryngol, 68:526-36.

Langveldt TPN, van Rossum MMA, Houtman EH, et al. 2001. Evaluation of voice quality in adductor spasmodic dysphonia before and after botulinum toxin treatment. Annals of Otol Rhynol Laryngol, 110:627-34.

Linville SE. 1996. The sound of senescence. J Voice, 10:190-200.

Liss JM, Weismer G, Rosenbek JC. 1990. Selected acoustic characteristics of speech production in very old males. J Gerontol, 45:P35-45.

Liu TC, Irish JC, Adams SG, et al. 1996. Prospective study of patient subjective responses to botulinum toxin injection for spasmodic dysphonia. Journal of Otolaryngology, 25:66-74.

Ludlow CL. 1995. Management of spasmodic dysphonias. In: Rubin JC, Sataloff RT, Korovin GS, et al. eds. Diagnosis and treatment of voice disorders. New York: Igaku-Shoin Medical Publishing. p. 436-54.

Lundy DS, Lu FL, Casiano RR, et al. 1998. The effect of patient factors on response outcomes to Botox treatment of spasmodic dysphonia. Journal of Voice, 12:460-6.

Madruga de Melo EC, Lemos M, Aragao Ximenes Filho J, et al. 2003. Distribution of collagen in the lamina propria of the human vocal fold. Laryngoscope, 113:2187-91.

Malmgren LT, Fisher PJ, Bookman LM, et al. 1999. Age-related changes in muscle fiber types in the human thyroarytenoid muscle: an immunohistochemical and stereological study using confocal laser scanning microscopy. Otolaryngol Head Neck Surg, 121:441-51.

Malmgren LT, Gacek RR. 1981. Histochemical characteristics of muscle fiber types in the posterior cricoarytenoid muscle. Annals of Otology, Rhinology and Laryngology, 90:423-9.

Malmgren LT, Ringwood M. 1988. Aging of recurrent laryngeal nerve: an ultrastructural morphometric study. In: Fujimura O ed. Vocal physiology: voice production, mechanisms, and functions. New York: Raven Press.

Mardini IA, McCarter RJ, Neal GD, et al. 1987. Contractile properties of laryngeal muscles in young and old baboons. Am J Otolaryngol, 8:85-90.

Mehta RP, Goldman SN, Orloff LA. 2001. Long-term therapy for spasmodic dysphonia: acoustic and aerodynamic outcomes. Archives of Otolaryngology-Head and Neck Surgery, 127.

Miller RH, Woodson GE, Jankovic J. 1987. Botulinum toxin injection of the vocal fold for spasmodic dysphonia: a preliminary report. Archives of Otolaryngology-Head and Neck Surgery, 113:603-5.

Morris R, Brown W. 1987. Age-related voice measures among adult women. Journal of Voice, 1:38-43.

Morris R, Brown W. 1994. Age-related differences in speech intensity among adult females. Folia Phoniatrica, 46:64-9.

Mortelliti AJ, Malmgren LT, Gacek RR. 1990. Ultrastructural changes with age in the human superior laryngeal nerve. Arch Otolaryngol Head Neck Surg, 116:1062-9.

Nagai H, Ota F, Connor NP. 2005. Effect of deficits in laryngeal sensation on laryngeal muscle biochemistry. Ann Otol Rhinol Laryngol, $114: 352-60$
Noell G. 1962. [On the problem of age-related changes of the laryngeal mucosa.]. Arch Ohren Nasen Kehlkopfheilkd, 179:361-5.

Orlikoff RF. 1990. The atherosclerotic voice. Ear Nose Throat J, 69:833-7.

Périé S, St Guily JL, Callard P, et al. 1997. Innervation of adult human laryngeal muscle fibers. Journal of the Neurological Sciences, 149:81-6.

Pestronk A, Drachman DB. 1978. The effect of aging on nerve sprouting. Trans Am Neurol Assoc, 103:14-8.

Prakash YS, Sieck GC. 1998. Age-related remodeling of neuromuscular junctions on type-identified diaphragm fibers. Muscle Nerve, 21:887-95.

Ramig LA, Ringel RL. 1983. Effects of physiological aging on selected acoustic characteristics of voice. J Speech Hear Res, 26:22-30.

Rhew K, Fiedler DA, Ludlow CL, et al. 1994. Technique for injection of Botulinum toxin through the flexible nasolaryngoscope'. OtolaryngologyHead and Neck Surgery, 787-94.

Rodeno MT, Sanchez-Fernandez JM, Rivera-Pomar JM. 1993. Histochemical and morphometrical ageing changes in human vocal cord muscles. Acta Otolaryngol, 113:445-9.

Salvatore AP, Cannito MP, Biswas A, et al. 2007. Longitudinal Study of Temporal Speech Alterations in an Individual with Adductor Spasmodic Dysphonia Treated with Botulinum Toxin. Journal of Medical SpeechLanguage Pathology, 15:67-82.

Sapienza CM, Cannito MP, Murry T, et al. 2002. Acoustic variations in reading produced by speakers with spasmodic dysphonia pre-botox injection and within early stages of post-botox injection. Journal of Speech and Hearing Research, 45:830-43.

Sato K, Hirano M. 1997. Age-related changes of elastic fibers in the superficial layer of the lamina propria of vocal folds. Ann Otol Rhinol Laryngol, 106:44-8.

Sato K, Hirano M. 1998. Age-related changes in the human laryngeal glands. Ann Otol Rhinol Laryngol, 107:525-9.

Sato K, Hirano M, Nakashima T. 2002. Age-related changes of collagenous fibers in the human vocal fold mucosa. Ann Otol Rhinol Laryngol, 111:15-20.

Sato K, Hirano M, Nakashima T. 2004. Age-related changes in vitamin A--storing stellate cells of human vocal folds. Ann Otol Rhinol Laryngol, 113:108-12.

Sato T, Tauchi H. 1982. Age changes in human vocal muscle. Mech Ageing Dev, 18:67-74.

Schantz EJ, Johnson EA. 1992. Properties and use of botulinum toxin and other microbial neurotoxins in medicine. Microbiol Rev, 56:80-99.

Scukanec GP, Petrosino L, Colcord RD. 1996. Age-related differences in acoustical aspects of contrastive stress in women. Folia Phoniatr Logop, 48:231-9.

Shaari CM, George E, Wu BL, et al. 1991. Quantifying the spread of botulinum toxin through muscle fascia. Laryngoscope, 101:960-4.

Simpson LL. 1992. Clinically relevant aspects of the mechanism of action of botulinum neurotoxin. Journal of Voice, 6:358-64.

Suzuki T, Connor NP, Lee K, et al. 2002. Age-related alterations in myosin heavy chain isoforms in rat intrinsic laryngeal muscles. Ann Otol Rhinol Laryngol, 111:962-7.

Suzuki T, Connor NP, Lee K, et al. 2002. Laryngeal-respiratory kinematics are impaired in aged rats. Ann Otol Rhinol Laryngol, 111:684-9.

Takeda N, Thomas GR, Ludlow CL. 2000. Aging effects on motor units in the human thyroarytenoid muscle. Laryngoscope, 110:1018-25.

Tanaka S, Hirano M, Chijiwa K. 1994. Some aspects of vocal fold bowing. Ann Otol Rhinol Laryngol, 103:357-62.

Thibeault SL, Li W, Gray SD, et al. 2002. Instability of extracellular matrix gene expression in primary cell culture of fibroblasts from human vocal fold lamina propria and tracheal scar. Ann Otol Rhinol Laryngol, 111:8-14.

Truong DD, Rontal M, Rolnick M, et al. 1991. Double-blind controlled study of Botulinum toxin in adductor spasmodic dysphonia. Laryngoscope, 101:630-4.

Whurr R, Lorch M, Fontana H, et al. 1993. The use of botulinum toxin in the treatment of adductor spasmodic dysphonia. J Neurol Neurosurg Psychiatry, 56:526-30. 
Wingate JM, Ruddy BH, Lundy DS, et al. 2005. Voice handicap index results for older patients with adductor spasmodic dysphonia. $J$ Voice, 19:124-31.

Woo P, Casper J, Colton R, et al. 1992. Dysphonia in the aging: physiology versus disease. Laryngoscope, 102:139-44.

Woodson GE. 1994. Determining the optimal dose for botulinum toxin in spasmodic dysphonia, paper presented to The Third International Symposium on Phonosurgery. Kyoto, Japan.

Xue SA, Hao GJ. 2003. Changes in the human vocal tract due to aging and the acoustic correlates of speech production: a pilot study. $J$ Speech Lang Hear Res, 46:689-701.

Zuber M, Sebald M, Bathien N, et al. 1993. Botulinum antibodies in dystonic patients treated with type A botulinum toxin: frequency and significance. Neurology, 43:1715-8. 
